\title{
Vaspin Alleviates Pathological Cardiac Hypertrophy By Regulating Autophagy-Dependent Myocardial Senescence
}

\author{
Haiying Rui \\ Shandong University \\ Ruochuan Li \\ Shandong University \\ Lulu Liu \\ Shandong University \\ Ziqi Han \\ Shandong University \\ Huaxiang Yu \\ Shandong University \\ Dandan Qin \\ Shandong University \\ Xiaohui Gong \\ Shandong University \\ Shengchuan Cao \\ Shandong University \\ Qiuhuan Yuan \\ Shandong University \\ Feng Xu \\ Shandong University \\ Li Xue ( $\nabla$ dream2005xl@126.com ) \\ Shandong University \\ Yuguo Chen \\ Shandong University
}

Original investigation

Keywords: Vaspin, Pathological cardiac hypertrophy, Autophagic flux, Myocardial senescence

Posted Date: November 18th, 2020

DOI: https://doi.org/10.21203/rs.3.rs-107249/v1 
License: (c) (i) This work is licensed under a Creative Commons Attribution 4.0 International License. Read Full License 
Vaspin alleviates pathological cardiac hypertrophy by regulating autophagy-dependent myocardial senescence

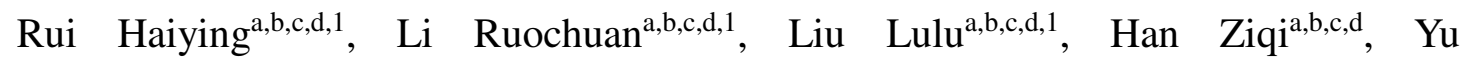
Huaxiang $^{\mathrm{a}, \mathrm{b}, \mathrm{c}, \mathrm{d}}$, Qin Dandan ${ }^{\mathrm{a}, \mathrm{b}, \mathrm{c}, \mathrm{d}}$, Gong Xiaohui ${ }^{\mathrm{a}, \mathrm{b}, \mathrm{c}, \mathrm{d}}$, Cao Shengchuan ${ }^{\mathrm{a}, \mathrm{b}, \mathrm{c}, \mathrm{d}}$, Yuan

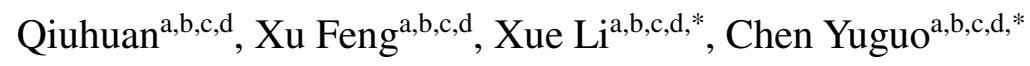

${ }^{\text {a }}$ Department of Emergency Medicine and Chest Pain Center, Qilu Hospital of Shandong University, Jinan, China

${ }^{\mathrm{b}}$ Shandong Provincial Clinical Research Center for Emergency and Critical Care Medicine, Institute of Emergency and Critical Care Medicine of Shandong University, Qilu Hospital of Shandong University, Jinan, China

${ }^{c}$ Key Laboratory of Emergency and Critical Care Medicine of Shandong Province, Key Laboratory of Cardiopulmonary-Cerebral Resuscitation Research of Shandong Province, Shandong Provincial Engineering Laboratory for Emergency and Critical Care Medicine, Qilu Hospital of Shandong University, Jinan, China

${ }^{\mathrm{d}}$ The Key Laboratory of Cardiovascular Remodeling and Function Research, Chinese Ministry of Education, Chinese Ministry of Health and Chinese Academy of Medical Sciences; The State and Shandong Province Joint Key Laboratory of Translational Cardiovascular Medicine; Qilu Hospital of Shandong University, Jinan, China

${ }^{1}$ Both authors contributed equally to this work.

* Correspondence authors at: Department of Emergency Medicine and Chest Pain Center, Qilu Hospital, Shandong University, Jinan 250012, China 
Email: dream2005x1@126.com (Xue Li), chen919085@sdu.edu.cn (Chen Yuguo).

\begin{abstract}
Background: Visceral adipose tissue-derived serine protease inhibitor (vaspin), a secretory adipokine, was reported to play a protective role in insulin resistance. Recent studies have demonstrated that serum vaspin levels are downregulated in patients with coronary artery disease (CAD) and that vaspin has a protective effect on myocardial ischaemia/reperfusion injury (IRI) and atherosclerosis. However, whether vaspin exerts specific effects on pathological cardiac hypertrophy remains unknown.
\end{abstract}

Methods: Pathologic cardiac hypertrophy was induced in male C57BL/6J wild-type (WT) and vaspin-knockout (vaspin-ko) mice. Buparlisib (PI3K inhibitor, $50 \mathrm{mg} / \mathrm{kg}$ ), rapamycin (mTOR inhibitor, $20 \mathrm{mg} / \mathrm{kg}$ ), or A-769662 (AMPK agonist, $30 \mathrm{mg} / \mathrm{kg}$ ) were pre- and co-administered to vaspin-ko mice daily for a period of 15 days. Induction of pathological cardiac hypertrophy was performed by the subcutaneous administration of isoproterenol (ISO) $(5 \mathrm{mg} / \mathrm{kg})$ into mice from the 7 th to the 15 th day. Cardiac hypertrophy, fibrosis, and cardiac function were examined in these mice. Critical characteristics of senescence (senescence-associated $\beta$-galactosidase activity and expression of cyclin-dependent kinase inhibitors) were examined in the cardiac hypertrophy model.

Results: We provide the first evidence that the serum level of vaspin decreased during pathological cardiac hypertrophy; further, knocking out of vaspin resulted in markedly exaggerated cardiac hypertrophy and fibrosis, and increased cardiomyocyte 
senescence in mice treated with ISO. Conversely, the administration of exogenous recombinant human vaspin in vitro protected myocardial cells against hypertrophy and senescence caused by ISO Mechanistically, PI3K-AKT-mTOR pathway-dependent activation of autophagic flux was involved in the protective effects of vaspin toward cardiac hypertrophy.

Conclusion: Our results showed for the first time that vaspin functions as a critical regulator that alleviates pathological cardiac hypertrophy by regulating autophagy-dependent myocardial senescence, which provides potential preventive and therapeutic targets for pathological cardiac hypertrophy.

Keywords: Vaspin, Pathological cardiac hypertrophy, Autophagic flux, Myocardial senescence

\section{Background}

Pathological cardiac hypertrophy, as the cellular response to increased haemodynamic load or neurohumoural stimuli [1], is a common result occurring during the harmful development of diseases like hypertension and myocardial infarction (MI). This hypertrophy leads to several severe cardiac events, including increased susceptibility to ischaemia/reperfusion injury (IRI), arrhythmias, cardiomyopathies, heart failure, and sudden death [2, 3]. Despite the progresses in the pathological cardiac hypertrophy therapy, it is still one of the primary causes of death in most of the world. Hence, illustration of the mechanisms underlying the development of myocardial hypertrophy is vital to explore efficient therapeutic tactics for the prevention and cure 
of pathological cardiac hypertrophy.

Visceral adipose tissue-derived serine protease inhibitor (vaspin), a member of the serine protease inhibitor family, was first identified in visceral white adipose tissues of the Otsuka Long-Evans Tokushima fatty (OLEFT) rat [4] and was later found in visceral and subcutaneous adipose tissues in obese humans [5]. Previous reports showed that vaspin could alleviate insulin resistance, obesity, metabolic disturbance, and hepatic steatosis through autocrine and paracrine mechanisms [6]. Recently, it has also been shown that vaspin prevents atherosclerosis development and reduces the risk of cardiovascular diseases $[7,8]$. Vaspin also plays a protective role in myocardial injury caused by ischaemia/reperfusion and diabetes, and its mechanism is related to the regulation of apoptosis, inflammation, and autophagy [9, 10]. For example, our previous study found that vaspin has protective effects against myocardial IRI through upregulating autophagic flux [11]. Whether vaspin can affect pathological cardiac hypertrophy remains unknown and requires further investigation.

Premature myocardial senescence, which is observed in stress-induced pathological cardiac hypertrophy, has been suggested as a significant cause of cardiac dysfunction $[12,13]$. Myocytes undergoing senescence show distinctive functional alterations including increases in the expression of cell cycle regulatory molecules, senescence-associated $\beta$-galactosidase (SA- $\beta$-gal) activity and senescence-associated secretory phenotype (SASP). Cardiomyocyte senescence and hypertrophy share some certain features: an increase in cardiomyocyte size and enhanced protein synthesis such as atrial natriuretic polypeptide (ANP), brain natriuretic peptide (BNP), and 
myosin heavy chain $\beta$ ( $\beta$-MHC) [14]. Dysfunctional cardiac autophagy, which results in the accumulation of misfolded proteins or toxic metabolites in the heart, has been reported as an important mechanism both in cardiomyocyte senescence [15] and in pathological hypertrophy [16]. However, whether premature cardiomyocyte senescence involved in stress-induced pathological cardiac hypertrophy is due to abnormal autophagy should be considered.

In this study, we evaluated the role of vaspin in pathological cardiac hypertrophy and explored the mechanisms. We hypothesized that vaspin alleviates pathological cardiac hypertrophy by regulating autophagy-dependent myocardial senescence.

\section{Materials and methods}

\section{Animals and experimental procedures}

The target exon DNA sequence of the Tec gene was cut by the CRISPR system, making a DSB, resulting in a frameshift mutation by the NHEJ DNA repair mechanism, resulting in Serpina12 knockout mice. C57BL/6 male mice (8-10 weeks old) were purchased from Huafukang Company (Beijing, China) and fed in the experimental animal centre of Qilu Hospital, Shandong University (Jinan, China). The mice were housed in rooms with free access to food and water and at a constant temperature with 12-h light/dark cycles. All animal procedures complied with the National Institute of Health Guide for Care and were approved by the Ethics Committee of Qilu Hospital of Shandong University. An in vivo study was conducted using a cardiac hypertrophy model established by subcutaneous injection of ISO (5 
$\mathrm{mg} / \mathrm{kg} / \mathrm{d}$, dissolved in saline, Sigma Aldrich, USA) once daily for 9 days, according to previous studies [17]. The mice were treated with the following: (a) Daily gavage treatments of a vehicle (1\%CMC-Na) and $50 \mathrm{mg} / \mathrm{kg}$ Buparlisib (S2247, Selleck) once a day for 15 days with ISO injected subcutaneously on the last 9 days; (b) Daily intraperitoneal injection of solvent control (2\% DMSO+30 \% PEG300+5 \% Tween $80+63 \% \mathrm{ddH}_{2} \mathrm{O}$ ) and $20 \mathrm{mg} / \mathrm{kg}$ Rapamycin (S1039, Selleck) once a day for 15 days with ISO injected subcutaneously on the last 9 days; (c) Daily intraperitoneal injection of solvent control (5\% DMSO+40\% PEG300+5\% Tween80+50\% dd $\left.\mathrm{H}_{2} \mathrm{O}\right)$ and $30 \mathrm{mg} / \mathrm{kg} \mathrm{A-769662} \mathrm{(S2697,} \mathrm{Selleck)} \mathrm{once} \mathrm{a} \mathrm{day} \mathrm{for} 15$ days with ISO injected subcutaneously on the last 9 days. Buparlisib is a selective Class I PI3K inhibitor. Rapamycin is a specific mTOR inhibitor. A-769662 is an effective AMPK activator.

\section{Cell culture and treatments}

The rat cardiomyoblast cell line H9c2 SV40 was cultured in DMEM supplemented with $10 \%$ foetal bovine serum (FBS), penicillin $(100 \mathrm{U} / \mathrm{mL})$ and streptomycin $(100$ $\mu \mathrm{g} / \mathrm{mL}$ ) in a humidified incubator with $5 \% \mathrm{CO}_{2}$ at $37^{\circ} \mathrm{C}$. Cells were serum-starved by changing to a medium containing $0.1 \%$ FBS and then treated for $48 \mathrm{~h}$ with ISO (10 $\mu \mathrm{mol} / \mathrm{L}$ ) to induce hypertrophy based on previous studies [18]. Human recombinant vaspin (40 $\mu \mathrm{g} / \mathrm{L}, 130-11$, Peprotech) and chloroquine diphosphate (10 mM, S4157, Selleck) were added $1 \mathrm{~h}$ before ISO stimulation.

\section{Echocardiography}


Measurement of mouse cardiac function was carried out by a Visualsonics high-resolution Vevo 2100 system. After removal of the hair of the anterior chest, mice were anaesthetized with $1.5 \%$ isoflurane. Related parameters (left ventricular ejection fraction, LVEF and fractional shortening, FS) were taken from the LV parasternal long axis (B-mode) and short axis (M-mode). For analysis, three images from consecutive cardiac cycles were analysed and averaged. The depth of anaesthesia was set to maintain the heart rate at approximately 550 beats per minute.

\section{Immunostaining}

After fixation with $4 \%$ paraformaldehyde at room temperature for $30 \mathrm{~min}, \mathrm{H} 9 \mathrm{c} 2$ cells were washed three times with ice-cold PBS, permeabilized with $0.1 \%$ Triton X-100 for 15 min, blocked with $1 \%$ bovine serum albumin for $30 \mathrm{~min}$, and stained with P21 antibody in blocking medium overnight at $4{ }^{\circ} \mathrm{C}$. Then, the samples were incubated with secondary antibody at room temperature for $1 \mathrm{~h}$. DAPI was added for nuclear counterstaining.

\section{Histological Analysis}

For histological analysis, hearts were fixed in $4 \%$ paraformaldehyde at room temperature for more than $24 \mathrm{~h}$. Fixed hearts were embedded in paraffin and cut transversely into $5-\mu \mathrm{m}$ sections. Serial heart sections were stained with haematoxylin-eosin or wheat germ agglutinin (Biotium, 29022) to measure myocyte cross-sectional areas. The degree of collagen deposition was detected by picrosirius 
red staining kit (Solarbio, S8060) and Masson staining kit (Leagene, DC0033).

\section{Elisa}

The levels of vaspin were determined in serum using commercially available ELISA kits (SEA706Mu; Cloud-Clone Crop.) according to the manufacturer's protocols.

\section{SA- $\beta$-gal Staining}

A senescence $\beta$-Galactosidase Staining Kit (CST, \#9860) was utilized in vitro according to the instruction manual. In vivo, fresh heart tissues were incubated in artificial SA- $\beta$-gal staining solution overnight at $37^{\circ} \mathrm{C}$ after washing in PBS. After that step, the hearts were placed in OCT compound (SAKURA, 4583) and cut into 10- $\mu \mathrm{m}$ sections to take pictures with microscopy (Olympics, IX73+DP73).

\section{Western blot analysis}

The concentration of total proteins extracted from the frozen hearts or collected cells was measured with a BCA protein assay (AR0146, Boster). Protein samples (20 $\mu \mathrm{g})$ were separated by SDS-PAGE and then transferred to PVDF membranes (Millipore). After blocking with $5 \%$ milk for $1 \mathrm{~h}$ at room temperature and then incubated overnight at $4^{\circ} \mathrm{C}$ with the following primary antibodies: GAPDH (CST, 97166), LC3B (Abcam, ab50967), P62 (CST, 39786), P16 (Abcam, ab51243), P53 (CST, 2524), P21 (Abcam, ab109199), $\gamma$-H2AX (CST, 9718), PI3K (CST, 4249), mTOR (CST, 2983), P-mTOR (CST, 5536), AKT (CST, 4691), P-AKT (CST, 4060), AMPK 
(CST, 4150), P-AMPK (CST, 4186), Beclin-1 (CST, 3495). The membranes were then incubated with the corresponding HRP-conjugated secondary antibodies for $1 \mathrm{~h}$ at room temperature. The membranes were detected with an Amersham Imager 600 (GE, Boston, USA) and were analysed with ImageJ Software (National Institutes of Health, Bethesda, MD, USA). All data were normalized to GAPDH internal control data.

\section{Evaluation of fluorescent LC3 puncta}

The method of evaluating the changing fluorescent LC3 puncta is the tandem RFP-GFP-LC3 construct described previously [19]. Before treatment, H9c2 cells were transfected with Ad-RFP-GFP-LC3 (ViGene Biosciences Company) at an MOI of 50. The green and red fluorescence intensities were observed under a laser confocal microscope (LSM780; Carl Zeiss AG, Jena, Germany).

\section{Electron microscopy}

H9c2 cells were fixed in $2.5 \%$ glutaraldehyde overnight. The samples were immersed in $1 \%$ osmium tetroxide in $0.1 \mathrm{mmol} / \mathrm{L}$ cacodylate buffer for $1 \mathrm{~h}$ after rinsing in 0.1 mmol/L cacodylate buffer with $1 \%$ tannic acid. After being rinsed again, the samples were dehydrated with alcohol and embedded in Epon 812. The samples were examined using a transmission electron (HT7700, Hitachi, Japan).

\section{RNA extraction and real-time PCR}

Total RNA was extracted by TRIzol (Life, 15596018) and then reverse transcribed 
into cDNA using the Prime Script RT reagent kit (Takara, R047A). RT-qPCR was performed using the Takara kit (RR420A) on the ABI7500 Real-time PCR System. The relative level of mRNA was calculated by the comparative CT method with $18 \mathrm{~S}$ mRNA as the invariant control.

\section{Statistical analysis}

All data are expressed as the means \pm SEM. Evaluation was performed using Student's t-test for two groups and one-way ANOVA for multiple groups. A value of $\mathrm{P}$ $<0.05$ was considered significant.

\section{Results}

\section{Vaspin-ko aggravated ISO-induced cardiac hypertrophy in vivo}

To explore the effects of vaspin on cardiac remodelling in an ISO-induced mouse model of myocardial hypertrophy, we randomly divided WT mice and vaspin-ko mice into two groups: the experimental group was subjected to subcutaneous injection with ISO, and the same amount of saline was used in the control group. No detectable plasma vaspin levels were found in the vaspin-ko mice, and the serum level of vaspin decreased during cardiac hypertrophy (Fig. 1A). WT and vaspin-ko mice were subjected to functional cardiac phenotyping. Significantly, ISO caused worse echocardiography-detectable cardiac function in vaspin-ko mice, as evidenced by decreases in cardiac ejection fraction and fractional shortening (Fig. 1B-C). The WT mice injected with ISO had an increased heart weight-to-body weight ratio (HW/BW) 
compared with that of WT mice injected with saline, and HW/BW was further enhanced in vaspin-ko mice injected with ISO (Fig. 1D). Hypertrophic remodelling and fibrosis of the myocardial tissues were significant in vaspin-ko mice injected with ISO compared with those in WT mice injected with ISO (Fig. 1E-F). Consistently, the quantitative real-time polymerase chain reaction results showed that these hypertrophic pathological phenotypes were accompanied by the upregulation of hypertrophic genes ANP (atrial natriuretic polypeptide), BNP (brain natriuretic peptide), and $\beta$-MHC (myosin heavy chain $\beta$ ), as well as fibrotic genes CTGF (connective tissue growth factor), Col1a1 (collagen 1a1), and Col3a1 (collagen 3a1) (Fig. 1G). These findings indicate that vaspin can prevent the progression of pathological cardiac hypertrophy caused by ISO.

\section{Vaspin-ko aggravated ISO-induced premature myocardial senescence in vivo}

To verify whether vaspin can regulate ISO-induced premature myocardial senescence, key senescent markers were examined in the cardiac hypertrophy model described before. We detected SA- $\beta$-gal activity in tissue sections, and positively stained cardiomyocytes were observed in WT mice after ISO treatment. In contrast, the ratio of SA- $\beta$-gal-positive cardiomyocytes was further increased in vaspin-ko mice treated with ISO (Fig. 2A). This conclusion was further confirmed by the results of immunohistochemistry that vaspin-ko mice showed increased senescence marker P16 levels compared with those of WT mice treated with ISO (Fig. 2B). Elevated levels of CDKIs, which block cell cycles, are one of the classic mechanisms of mitotic cell 
senescence. One common denominator of ageing is the consequence of increased DNA damage accumulation [20-23]. The western blot results demonstrated that the protein expression of $\mathrm{P} 16, \mathrm{P} 53, \mathrm{P} 21$, and $\gamma$-H2AX significantly increased in vaspin-ko mice treated with ISO compared with WT mice after ISO treatment (Fig. 2C). Taken together, these data suggest that vaspin plays an essential role in alleviating premature myocardial senescence in pathological myocardial hypertrophy.

Vaspin-ko aggravated ISO-induced autophagy reduction in vivo, and recombinant human vaspin can rescue the ISO-induced autophagy decline in vitro

Pathological cardiac hypertrophy induced by ageing and stress is linked to impaired protein homeostasis and autophagy. We evaluated the effect of vaspin on autophagy in the ISO-induced cardiac hypertrophy model. The protein expression levels of P62 and LC3II were measured as markers of autophagy and autophagosome formation. It was shown that the protein expression of LC3-II/LC3-I was reduced and P62 was increased in the pathological process of myocardial hypertrophy of WT mice. The phenomenon was more obvious in vaspin-ko mice (Fig. 3A). We then detected the upstream signalling pathway regulating autophagy. The expression levels of proteins, including PI3K, P-AKT and P-mTOR, were upregulated during cardiac hypertrophy in WT mice, while P-AMPK was simultaneously downregulated. These changes were further enhanced in vaspin-ko mice with ISO treatment (Fig. 3B). As shown in Fig. 3C, vaspin upregulated LC3-II/LC3-I protein expression and downregulated P62 
protein expression in a time-dependent manner in H9c2 cells. Recombinant human vaspin rescued the decline in ISO-induced autophagosomes and autolysosomes in H9c2 cells captured by electron microscopy (Fig. 3D). To further demonstrate the effect of vaspin on autophagic flux, H9c2 cells were transfected with RFP-GFP-LC3B virus. The autophagic flux was then examined, including the biogenesis and maturation of autophagosomes (GFP-LC3, green puncta) and acidic autolysosomes (RFP-LC3, red puncta), in which GFP was degraded by lysosomes. As shown in Fig. 3E, the puncta representing autophagosomes and autolysosomes increased significantly after vaspin treatment, indicating that vaspin exerted promotive and reparative effects on autophagic flux. These findings indicate that vaspin can improve impaired autophagy in ISO-induced pathological myocardial hypertrophy in vivo and vitro.

\section{Vaspin alleviates cardiomyocyte hypertrophy and senescence by regulating autophagy in vitro}

To detect whether vaspin affects autophagy-dependent cardiomyocyte senescence and improves cardiomyocyte hypertrophy in vitro. Cardiomyocyte hypertrophy and the phenotype of premature cardiomyocyte senescence were detected under the intervention of recombinant human vaspin and the autophagy inhibitor chloroquine diphosphate (CQ). The results of SA- $\beta$-gal staining showed that vaspin could reverse the cardiomyocyte senescence phenotype in the ISO-induced cardiomyocyte hypertrophy model, which was blocked by CQ (Fig. 4A). Immunofluorescence 
staining for P21 presented similar results (Fig. 4B). The protein expression levels of P16, P21, P53, and $\gamma$-H2AX were consistent with previous experimental results (Fig. 4C). The mRNA expression of hypertrophic and fibrotic genes was also reduced after the administration of vaspin recombinant protein, but this benefit disappeared after autophagic flux was blocked (Fig. 4D). Taken together, these data suggest that vaspin plays a protective role in autophagy-dependent cardiomyocyte senescence, which may explain why the administration of vaspin can improve myocardial hypertrophy.

The protective effect of vaspin on premature myocardial senescence and cardiac hypertrophy depends on the PI3K-AKT-mTOR pathway-dependent activation of autophagy

To determine the specific target of vaspin in regulating cardiac hypertrophy and myocardial senescence, three autophagy activators were pre-treated and co-treated into vaspin-ko mice daily for a period of 15 days. The subcutaneous administration of ISO induced pathological cardiac hypertrophy from the 7th to the 15th day (Fig. 5A). The results showed that the PI3K inhibitor and mTOR inhibitor could inhibit premature myocardial senescence and improve pathological myocardial hypertrophy in vaspin-ko mice. However, such a phenomenon was not observed following treatment with the AMPK agonist (Fig. 5B-G). Taken together, these results show that vaspin can protect against myocardial hypertrophy and myocardial senescence through PI3K-AKT-mTOR pathway-dependent activation of autophagy (Fig. 6). 


\section{Discussion}

Here, we found that the serum level of vaspin decreased during pathological cardiac hypertrophy and that vaspin-ko markedly exaggerated cardiac hypertrophy, fibrosis, and cardiomyocyte senescence in mice with ISO treatment. Moreover, administration of exogenous recombinant human vaspin protected myocardial cells against hypertrophy and senescence caused by ISO in vitro. Mechanistically, PI3K-AKT-mTOR pathway-dependent activation of autophagic flux was involved in the protective effects of vaspin on cardiac hypertrophy. Taken together, these data suggest that vaspin may alleviate pathological cardiac hypertrophy by regulating autophagy-dependent myocardial senescence.

Although an increasing number of clinical trials have found that serum vaspin levels are closely related to diabetes, obesity, rheumatoid arthritis, polycystic ovary syndrome, and cardiovascular disease [24-27], there was no significant evidence in the relationship of vaspin and cardiac hypertrophy. Our results are the first to report that the serum vaspin level is significantly decreased during ISO-induced pathological cardiomyocyte hypertrophy. One previous study has reported that male mouse cardiomyocytes show a hypertrophic response to a high-fat diet, accompanied by the increased expression of vaspin in pericardial adipose tissue [28]. High-fat or high-sugar stimulation can induce the increase of vaspin mRNA and protein expression in BAT [29], which may be a reason for the elevated level of vaspin under metabolic abnormality [28]. Thus, we speculate that the vaspin level is determined by the effects of stimulus on the expression of vaspin in adipose tissue in different 
causes-derived cardiac hypertrophy.

Among the complex signaling networks in which vaspin is involved in cardiovascular diseases, the distinct processes are autophagy abnormality, apoptosis, inflammation, and ER stress of endothelial cells, smooth muscle cells, macrophages, and myocardial cells. Vaspin can exert its anti-atherosclerotic effects by reducing endothelial apoptosis [30] and activating the insulin signal pathway (PI3K/AKT)-dependent endothelial nitric oxide synthase (eNOS) activity [31]. Our previous research results showed that vaspin protects against myocardial I/R injury via upregulating AMPK-mTOR-dependent autophagic flux and lysosomal function restoration [11]. Another study demonstrated that vaspin could improve the autophagy level of diabetic cardiomyopathy rats and alleviate the degree of myocardial apoptosis and fibrosis [10]. Therefore, improvement in autophagy associated with vaspin may contribute to the repair of cardiac damages. Furthermore, in the present study, vaspin alleviated pathological cardiomyocyte hypertrophy by upregulating PI3K-AktmTOR-dependent autophagy, suggesting that vaspin may regulate autophagy through various pathways to protect heart under different stimuli.

In recent years, some studies have shown that autophagy is the molecular mechanism of cardiomyocyte hypertrophy, and the effect of autophagy on cardiomyocyte hypertrophy is a double-edged sword. The boost of the autophagy level could help recover hypertrophic cardiomyocytes in the model of myocardial hypertrophy induced by pressure. However, hyperactivation of autophagy is also involved in the process from stable cardiac hypertrophy to decompensated heart 
failure [32]. The stimulation concentration of vaspin $(40 \mu \mathrm{g} / \mathrm{L})$ used in this experiment upregulated autophagic flux by increasing autophagosome and restoring lysosome function, without overregulating autophagy causing autophagic cell death. This indicated that the $40 \mu \mathrm{g} / \mathrm{L}$ dose of vaspin had a protective effect on pathologic cardiac hypertrophy.

It has been shown that senescence progression might be associated with multiple physiological and pathological processes of cardiovascular diseases. Myocardial senescence is one of the critical risk factors for cardiac hypertrophy. Recent evidence suggests that the cellular senescence phenotype is involved in the process of heart remodeling caused by diabetes, obesity, chemotherapy drugs, and dilated cardiomyopathy [33-37]. The central finding is that senescent cells can potentially be eliminated for the treatment of ageing-related diseases [38]. Moreover, the non-ageing-related pathological cardiac hypertrophy caused by AngII and ISO could be inhibited by anti-ageing factors and compounds such as resveratrol, metformin, and senescence marker protein 30 (SMP30) [39-41]. Therefore, the above research results have opened the door for the development of agents and strategies to target senescent cells, specifically for the prevention and treatment of heart failure. Currently, our study found that the senescence phenotype of cardiomyocytes was further aggravated in the hearts of vaspin-ko mice, and exogenous administration of vaspin reduced the senescence phenotype of cardiomyocytes. These data further verify the pathogenic role of myocardial senescence in cardiac hypertrophy, and indicate that exogenous vaspin supplement may play a protective role as a critical 
senescence regulator in future clinical trial for cardiac hypertrophy and heart failure.

\section{Conclusion}

Vaspin levels decrease during pathological cardiac hypertrophy, and exogenous recombinant human vaspin alleviates ISO-induced pathological cardiomyocyte hypertrophy and cardiomyocyte senescence by activating autophagy in a PI3K-Akt-mTOR pathway-dependent manner. These findings suggest that vaspin may act as a predictive indicator and a possible therapeutic target for pathological cardiac hypertrophy.

\section{Abbreviations}

CAD: coronary artery disease; vaspin: visceral adipose tissue-derived serine protease inhibitor; ISO: isoproterenol; IRI: ischaemia/reperfusion injury; MI: myocardial infarction; WT: wild type; KO: knockout; ANP: atrial natriuretic polypeptide; BNP: brain natriuretic peptide; $\beta$-MHC: myosin heavy chain $\beta$; CTGF: connective tissue growth factor; Col1a1: collagen 1a1; Col3a1: collagen 3a1; EF: ejection fraction; FS: fractional shortening; HW/BW: heart weight-to-body weight ratio; P16: cyclin-dependent kinase inhibitor 2A; P53: cellular tumour antigen P53; P21: cyclin-dependent kinase inhibitor $1 ; \gamma$-H2AX: histone H2AX; SA- $\beta$-gal: senescence-associated- $\beta$-galactosidase; SASP: $\quad$ senescence-associated secretory phenotype; P62: sequestosome-1; LC3B: microtubule-associated proteins 1A/1B light chain 3B; AMPK: AMP-activated protein kinase; mTOR: serine/threonine-protein 
kinase mTOR; PI3K: phosphoinositide 3-kinase regulatory subunit; AKT: rac-alpha serine/threonine-protein kinase; GAPDH: glyceraldehyde 3-phosphate dehydrogenase; DAPI: 4', 6-diamidino-2-phenylindole.

\section{Acknowledgments}

Not applicable.

\section{Authors' contributions}

RHY and XL: Conception; RHY, LRC, LLL, YHX, HZQ and QDD: Data collection; GXH, CSC, YQH, PJJ and CYG: Data analysis; XF, CYG and RHY: drafting of the manuscript, revision of the manuscript. All authors read and approved the final manuscript.

\section{Funding}

This study was supported by the National Key R \& D Program of China (2020YFC1512700, 2017YFC0908700, 2017YFC0908703), National S\&T Fundamental Resources Investigation Project (2018FY100600, 2018FY100602), National Natural Science Foundation of China (82030059, 81772036, 81873950, 81671951), Taishan Pandeng Scholar Program of Shandong Province (tspd20181220), Taishan Young Scholar Program of Shandong Province (tsqn20161065, tsqn201812129) and Key R\&D Program of Shandong Province (2019GSF108131, 2019GSF108075, 2017GSF218040). 


\section{Availability of data and materials}

All data are provided and available in this manuscript.

\section{Ethics approval and consent to participate}

This study was approved by the Qilu Hospital's ethics committee, Shandong University.

\section{Consent for publication}

All authors have read and approved the submission of the manuscript. The manuscript has not been published and is not being considered for publication elsewhere, in whole or in part, in any language. If the manuscript is accepted, we approve it for publication in Cardiovascular Diabetology.

\section{Competing interests}

The authors declare that they have no competing interests.

\section{Author details}

${ }^{a}$ Department of Emergency Medicine and Chest Pain Center, Qilu Hospital of Shandong University, Jinan, China. ${ }^{\mathrm{b}}$ Shandong Provincial Clinical Research Center for Emergency and Critical Care Medicine, Institute of Emergency and Critical Care Medicine of Shandong University, Qilu Hospital of Shandong University, Jinan, 
China. ${ }^{\mathrm{c}}$ Key Laboratory of Emergency and Critical Care Medicine of Shandong Province, Key Laboratory of Cardiopulmonary-Cerebral Resuscitation Research of Shandong Province, Shandong Provincial Engineering Laboratory for Emergency and Critical Care Medicine, Qilu Hospital of Shandong University, Jinan, China. ${ }^{\mathrm{d}}$ The Key Laboratory of Cardiovascular Remodeling and Function Research, Chinese Ministry of Education, Chinese Ministry of Health and Chinese Academy of Medical Sciences; The State and Shandong Province Joint Key Laboratory of Translational Cardiovascular Medicine; Qilu Hospital of Shandong University, Jinan, China.

\section{References}

1. B.H. Lorell. Transition from hypertrophy to failure. Circulation. 1997; 96:3824-3827.

2. N. Frey, E.N. Olson. Cardiac hypertrophy: the good, the bad, and the ugly. Annu Rev Physiol. 2003; 65:45-79.

3. J. Heineke, J.D. Molkentin. Regulation of cardiac hypertrophy by intracellular signalling pathways. Nat Rev Mol Cell Biol. 2006; 7:589-600.

4. K. Hida, J. Wada, H. Zhang, K. Hiragushi, Y. Tsuchiyama, K. Shikata, et al. Identification of genes specifically expressed in the accumulated visceral adipose tissue of OLETF rats. J Lipid Res. 2000; 41:1615-1622.

5. N. Kloting, J. Berndt, S. Kralisch, P. Kovacs, M. Fasshauer, M.R. Schon, et al. Vaspin gene expression in human adipose tissue: association with obesity and type 2 diabetes. Biochem Biophys Res Commun. 2006; 339: 430-436. 
6. A. Nakatsuka, J. Wada, I. Iseda, S. Teshigawara, K. Higashio, K. Murakami, et al. Vaspin is an adipokine ameliorating ER stress in obesity as a ligand for cell-surface GRP78/MTJ-1 complex. Diabetes. 2012; 61: 2823-2832.

7. Y. Lin, J. Zhuang, H. Li, G. Zhu, S. Zhou, W. Li, et al. Vaspin attenuates the progression of atherosclerosis by inhibiting ER stress-induced macrophage apoptosis in apoE-/- mice. Molecular medicine reports. 2016; 13:1509-1516.

8. H.L. Li, W.H. Peng, S.T. Cui, H. Lei, Y.D. Wei, W.M. Li, et al. Vaspin plasma concentrations and mRNA expressions in patients with stable and unstable angina pectoris. Clin Chem Lab Med. 2011; 49: 1547-1554.

9. Yuan L, Dai X, Fu H, Sui D, Lin L, Yang L, et al. Vaspin protects rats against myocardial ischemia/reperfusion injury (MIRI) through the TLR4/NF- $\mathrm{B}$ signaling pathway. Eur J Pharmacol. 2018; 835:132-139.

10. Li X, Ke X, Li Z, Li B. Vaspin prevents myocardial injury in rats model of diabetic cardiomyopathy by enhancing autophagy and inhibiting inflammation. Biochem Biophys Res Commun. 2019; 514: 1-8.

11. F. Yang, L. Xue, Z. Han, F. Xu, S. Cao, S. Dai, et al. Vaspin alleviates myocardial ischaemia/reperfusion injury via activating autophagic flux and restoring lysosomal function. Biochem Biophys Res Commun. 2018; 503: 501-507.

12. R.A. Boon, K. Iekushi, S. Lechner, T. Seeger, A. Fischer, S. Heydt, et al. MicroRNA-34a regulates cardiac ageing and function. Nature. 2013; 495:107-110. 
13. Nishimura, A., Shimauchi, T., Tanaka, T., Shimoda, K., Toyama, T., Kitajima, N., et al. Hypoxia-induced interaction of filamin with Drp1 causes mitochondrial hyperfission-associated myocardial senescence. Sci Signal. 2018; 11: eaat5185.

14. Y. Xing, T. Niu, W. Wang, J. Li, S. Li, J.S. Janicki, et al. Triterpenoid dihydro-CDDO-trifluoroethyl amide protects against maladaptive cardiac remodeling and dysfunction in mice: a critical role of Nrf2. PLoS One. 2012; 7:e44899.

15. Carmona-Gutierrez D, Zimmermann A, Kainz K, Pietrocola F, Chen G, Maglioni S, et al. The flavonoid 4,4'-dimethoxychalcone promotes autophagy-dependent longevity across species. Nat Commun. 2019; 10: 651.

16. Wang X, Cui T. Autophagy modulation: a potential therapeutic approach in cardiac hypertrophy. Am J Physiol Heart Circ Physiol. 2017; 313: H304-H319.

17. X. Ma, Y. Song, C. Chen, Y. Fu, Q. Shen, Z. Li, et al. Distinct actions of intermittent and sustained beta-adrenoceptor stimulation on cardiac remodeling. Sci China Life Sci. 2011; 54: 493-501.

18. M.Z. Chen, Q.T. Bu, S.C. Pang, F.L. Li, M.N. Sun, E.F. Chu, et al. Tetrodotoxin attenuates isoproterenol-induced hypertrophy in $\mathrm{H} 9 \mathrm{c} 2$ rat cardiac myocytes. Mol Cell Biochem. 2012; 371: 77-88.

19. S. Kimura, T. Noda, T. Yoshimori. Dissection of the autophagosome maturation process by a novel reporter protein, tandem fluorescent-tagged LC3. Autophagy. 2007; 3: 452-460.

20. W. Zheng, H. Wang, L. Xue, Z. Zhang, T. Tong. Regulation of cellular 
senescence and p16(INK4a) expression by Id1 and E47 proteins in human diploid fibroblast. J Biol Chem. 2004; 279: 31524-31532.

21. C. Lopez-Otin, M.A. Blasco, L. Partridge, M. Serrano, G. Kroemer. The hallmarks of aging. Cell. 2013; 153: 1194-1217.

22. R. Sun, B. Zhu, K. Xiong, Y. Sun, D. Shi, L. Chen, et al. Senescence as a novel mechanism involved in beta-adrenergic receptor mediated cardiac hypertrophy. PLoS One. 2017; 12: e0182668.

23. J.A. Sorrentino, H.K. Sanoff, N.E. Sharpless. Defining the toxicology of aging. Trends Mol Med. 2014; 20: 375-384.

24. M.A. Kobat, A. Celik, M. Balin, Y. Altas, A. Baydas, M. Bulut, et al. The investigation of serum vaspin level in atherosclerotic coronary artery disease. $\mathbf{J}$ Clin Med Res. 2012; 4: 110-113.

25. Aktaş HŞ, Uzun YE, Kutlu O, Pençe HH, Özçelik F, Çil EÖ, et al. The effects of high intensity-interval training on vaspin, adiponectin and leptin levels in women with polycystic ovary syndrome. Arch Physiol Biochem. 2019; 13:1-6.

26. Ozgen M, Koca SS, Dagli N, Balin M, Ustundag B, Isik A. Serum adiponectin and vaspin levels in rheumatoid arthritis. Arch Med Res. 2010; 41: 457-63.

27. Escoté X, Gómez-Zorita S, López-Yoldi M, Milton-Laskibar I, Fernández-Quintela A, Martínez JA, et al. Role of Omentin, Vaspin, Cardiotrophin-1, TWEAK and NOV/CCN3 in Obesity and Diabetes Development. Int J Mol Sci. 2017;18:1770.

28. C. Bohm, V. Benz, M. Clemenz, C. Sprang, B. Hoft, U. Kintscher, et al. Sexual 
dimorphism in obesity-mediated left ventricular hypertrophy. Am J Physiol Heart Circ Physiol. 2013; 305: H211-218.

29. Weiner J, Rohde K, Krause K, Zieger K, Klöting N, Kralisch S, et al. Brown adipose tissue (BAT) specific vaspin expression is increased after obesogenic diets and cold exposure and linked to acute changes in DNA-methylation. Mol Metab. 2017; 28: 482-493.

30. C.H. Jung, W.J. Lee, J.Y. Hwang, S.M. Seol, Y.M. Kim, Y.L. Lee, et al. Vaspin protects vascular endothelial cells against free fatty acid-induced apoptosis through a phosphatidylinositol 3-kinase/Akt pathway. Biochem Biophys Res Commun. 2011; 413: 264-269.

31. N. Sun, H. Wang, L. Wang. Vaspin alleviates dysfunction of endothelial progenitor cells induced by high glucose via PI3K/Akt/eNOS pathway. International journal of clinical and experimental pathology. 2015; 8: 482-489.

32. Guo R, Hu N, Kandadi MR, Ren J. Facilitated ethanol metabolism promotes cardiomyocyte contractile dysfunction through autophagy in murine hearts. Autophagy. 2012; 8:593-608.

33. S. Din, M.H. Konstandin, B. Johnson, J. Emathinger, M. Volkers, H. Toko, et al. Metabolic dysfunction consistent with premature aging results from deletion of Pim kinases. Circ Res. 2014; 115: 376-387.

34. B. Niemann, Y. Chen, M. Teschner, L. Li, R.E. Silber, S. Rohrbach. Obesity induces signs of premature cardiac aging in younger patients: the role of mitochondria. J Am Coll Cardiol. 2011; 57: 577-585. 
35. Miyata M, Suzuki S, Misaka T, Shishido T, Saitoh S-i, Ishigami A, et al. Senescence Marker Protein 30 Has a Cardio-Protective Role in Doxorubicin-Induced Cardiac Dysfunction. PLoS ONE. 2013; 8: e79093.

36. Y. Maejima, S. Adachi, H. Ito, K. Hirao, M. Isobe. Induction of premature senescence in cardiomyocytes by doxorubicin as a novel mechanism of myocardial damage. Aging Cell. 2008; 7: 125-136.

37. I. Gonzalez-Valdes, I. Hidalgo, A. Bujarrabal, E. Lara-Pezzi, L. Padron-Barthe, P. Garcia-Pavia, et al. Bmi1 limits dilated cardiomyopathy and heart failure by inhibiting cardiac senescence. Nat Commun. 2015; 6: 6473.

38. Childs B G, Gluscevic M, Baker D J, Laberge R M, Marquess D, Dananberg J, et al. Senescent cells: an emerging target for diseases of ageing. Nat Rev Drug Discov. 2017; 16:718-735.

39. R. Sun, B. Zhu, K. Xiong, Y. Sun, D. Shi, L. Chen, et al. Senescence as a novel mechanism involved in $\beta$-adrenergic receptor mediated cardiac hypertrophy. PLoS One. 2017; 12: e0182668.

40. T. Misaka, S. Suzuki, M. Miyata, A. Kobayashi, A. Ishigami, T. Shishido, et al. Senescence marker protein 30 inhibits angiotensin II-induced cardiac hypertrophy and diastolic dysfunction. Biochem Biophys Res Commun. 2013; 439: 142-147.

41. Tang X, Chen X, Wang N, Wang X, Liang S, Zheng W, et al. SIRT2 Acts as a Cardioprotective Deacetylase in Pathological Cardiac Hypertrophy. Circulation. 2017; 136: 2051-2067. 


\section{Figure Legends}

Fig. 1. The effects of vaspin on ISO-induced cardiac hypertrophy in vivo.

(A) Detection of plasma vaspin levels in WT and vaspin-ko mice injected with $\mathrm{NaCl}$ or ISO with an ELISA assay. (B-C) Cardiac function of WT and vaspin-ko mice injected with $\mathrm{NaCl}$ or ISO as shown by FS and EF obtained from echocardiography. (D) HW/BW of WT and vaspin-ko mice. (E) H\&E staining (scale bar=20 $\mu \mathrm{m}$ ) and WGA staining (scale bar $=50 \mu \mathrm{m}$ ) were performed to determine the hypertrophic growth of the hearts in WT and vaspin-ko mice injected with $\mathrm{NaCl}$ or ISO. (F) Picrosirius red staining (scale bar $=50 \mu \mathrm{m})$ and Masson staining (scale bar $=50 \mu \mathrm{m}$ ) were performed to determine fibrosis of the hearts in WT and vaspin-ko mice injected with $\mathrm{NaCl}$ or ISO. (G) RT-qPCR of $\beta$-MHC, ANP, BNP, CTGF, Col1a1, and Col3a1 in the heart of WT and vaspin-ko mice injected with $\mathrm{NaCl}$ or ISO. $\mathrm{n}=3-4$ per group. *P $<0.05$ vs $\mathrm{WT}+\mathrm{NaCl}$; ${ }^{\#} \mathrm{P}<0.05$ vs WT+ISO. FS fractional shortening, $E F$ ejection fraction, $H W / B W$ heart weight-to-body weight ratio, $H \& E$ haematoxylin-eosin, $W G A$ wheat germ agglutinin, $A N P$ atrial natriuretic polypeptide, $B N P$ brain natriuretic peptide, $\beta-M H C$ myosin heavy chain $\beta, C T G F$ connective tissue growth factor, Collal collagen 1a1, Col3al collagen $3 \mathrm{a} 1$

Fig. 2. The effects of vaspin on ISO-induced premature myocardial senescence in vivo.

(A-B) SA- $\beta$-gal staining pictures $\quad($ scale bar $=50 \mu \mathrm{m})$ and representative immunohistochemical pictures of P16 (scale bar $=50 \mu \mathrm{m}$ ) in heart sections of WT and vaspin-ko mice injected with $\mathrm{NaCl}$ or ISO. (C-D) Representative Western blot bands and quantification of senescence markers (P16, P21, P53, and $\gamma-\mathrm{H} 2 \mathrm{AX})$ proteins expression in WT and vaspin-ko mice injected with $\mathrm{NaCl}$ or ISO. $\mathrm{n}=3-4$ per group. *P $<0.05$ vs $\mathrm{WT}+\mathrm{NaCl} ;{ }^{\#} \mathrm{P}<0.05$ vs $\mathrm{WT}+\mathrm{ISO}$. SA- $\beta$-gal senescence-associated 
$\beta$-galactosidase, P16 cyclin-dependent kinase inhibitor 2A, P53 cellular tumour antigen P53, P21 cyclin-dependent kinase inhibitor $1, \gamma-H 2 A X$ histone $\mathrm{H} 2 \mathrm{AX}$, GAPDH glyceraldehyde 3-phosphate dehydrogenase

Fig. 3. The effects of vaspin on ISO-induced autophagy reduction in vivo and vitro.

(A-B) Representative Western blot bands and quantification of P62, LC3-II, P-AKT, P-mTOR, PI3K, and P-AMPK proteins expression in WT and vaspin-ko mice injected with $\mathrm{NaCl}$ or ISO. $\mathrm{n}=5$ per group. ${ }^{*} \mathrm{P}<0.05$ vs $\mathrm{WT}+\mathrm{NaCl} ;{ }^{*} \mathrm{P}<0.05$ vs $\mathrm{WT}+\mathrm{ISO}$. (C) Western blot analysis of time-dependent changes in LC3-II and P62 in H9c2 cells after vaspin treatment $(40 \mu \mathrm{g} / \mathrm{L})$. (D) Electron microscopy visualized autophagosomes and autolysosomes in hypertrophic $\mathrm{H} 9 \mathrm{c} 2$ cells treated with vaspin (scale bar=2.0 $\mu \mathrm{m}$ ). (E) Ad-RFP-GFP-LC3 was transfected to assess autophagic flux in hypertrophic H9c2 cells treated with vaspin $($ scale bar $=50 \mu \mathrm{m}) . \mathrm{n}=5$ per group. ${ }^{*} \mathrm{P}<0.05 ;{ }^{*} \mathrm{P}<0.05 . P 62$ sequestosome-1, $L C 3 B$ microtubule-associated proteins 1A/1B light chain 3B, AMPK AMP-activated protein kinase, $m T O R$ serine/threonine-protein kinase mTOR, $P I 3 K$ phosphoinositide 3-kinase regulatory subunit, $A K T$ rac-alpha serine/threonine-protein kinase, GAPDH glyceraldehyde 3-phosphate dehydrogenase

Fig. 4. The protective effect of vaspin on cardiomyocyte hypertrophy and senescence was blocked by the autophagic flux blocker CQ in vitro.

(A-B) SA- $\beta$-gal staining pictures (scale bar=50 $\mu \mathrm{m}$ ) and representative immunofluorescence staining images for DAPI (blue) and P21 (red) in hypertrophic H9c2 cells treated with vaspin and CQ (scale bar $=50 \mu \mathrm{m})$. (C) Representative Western blot bands and quantification of senescence markers (P16, P21, P53, and $\gamma$-H2AX) proteins expression. (D) RT-qPCR of ANP, BNP, Col1a1, and Col3a1. $n=4-5$ per group. $* \mathrm{P}<0.05$. SA- $\beta$-gal senescence-associated $\beta$-galactosidase, DAPI 4', 
6-diamidino-2-phenylindole, P16 cyclin-dependent kinase inhibitor 2A, P53 cellular tumour antigen P53, P21 cyclin-dependent kinase inhibitor 1, $\gamma$-H2AX histone H2AX, GAPDH glyceraldehyde 3-phosphate dehydrogenase, ANP atrial natriuretic polypeptide, BNP brain natriuretic peptide, Collal collagen 1a1, Col3al collagen 3a1

Fig. 5. The protective effect of vaspin on premature myocardial senescence and cardiac hypertrophy depends on the PI3K-AKT-mTOR pathway-dependent activation of autophagy.

(A) Experimental design assessing the autophagy pathway target of vaspin. (B) The cardiac function of vaspin-ko mice after ISO and different autophagy activator treatments as shown by EF and FS obtained from echocardiography. (C) H\&E staining (scale bar $=20 \mu \mathrm{m}$ ) and WGA staining (scale bar $=50 \mu \mathrm{m}$ ) were performed to determine the hypertrophic growth of the hearts in vaspin-ko mice injected with ISO and different autophagy activators. (D) Picrosirius red staining (scale bar=50 $\mu \mathrm{m}$ ) and Masson staining (scale bar $=50 \mu \mathrm{m}$ ) were performed to determine fibrosis of the hearts in vaspin-ko mice injected with ISO and different autophagy activators. (E) Representative immunohistochemical pictures of P16 in the heart sections of vaspin-ko mice after ISO and different autophagy activator treatments (scale bar=50 $\mu \mathrm{m})$. (F) Western blot analysis of senescence- and autophagy-associated markers in vaspin-ko mice injected with ISO and different autophagy activators. (G) Quantification of fibrotic gene and hypertrophic gene mRNA levels. $n=3-4$ per group. ${ }^{*} \mathrm{P}<0.05 . F S$ fractional shortening, $E F$ ejection fraction, $H \& E$ haematoxylin-eosin, $W G A$ wheat germ agglutinin, $A N P$ atrial natriuretic polypeptide, $B N P$ brain natriuretic peptide, CTGF connective tissue growth factor, Collal collagen 1a1, Col3al collagen 3a1, P16 cyclin-dependent kinase inhibitor 2A, P53 cellular tumour antigen P53, P21 cyclin-dependent kinase inhibitor $1, \gamma-H 2 A X$ histone $\mathrm{H} 2 \mathrm{AX}, G A P D H$ glyceraldehyde 
3-phosphate dehydrogenase, $L C 3 B$ microtubule-associated proteins $1 \mathrm{~A} / 1 \mathrm{~B}$ light chain 3B, AMPK AMP-activated protein kinase, $m T O R$ serine/threonine-protein kinase mTOR, PI3K phosphoinositide 3-kinase regulatory subunit

Fig. 6. The proposed molecular mechanisms of the protective effect of vaspin on pathological cardiac hypertrophy. In summary, vaspin is involved in ISO-induced cardiac hypertrophy by improving impaired autophagy and reducing the proportion of senescent cardiomyocytes. 
Figures

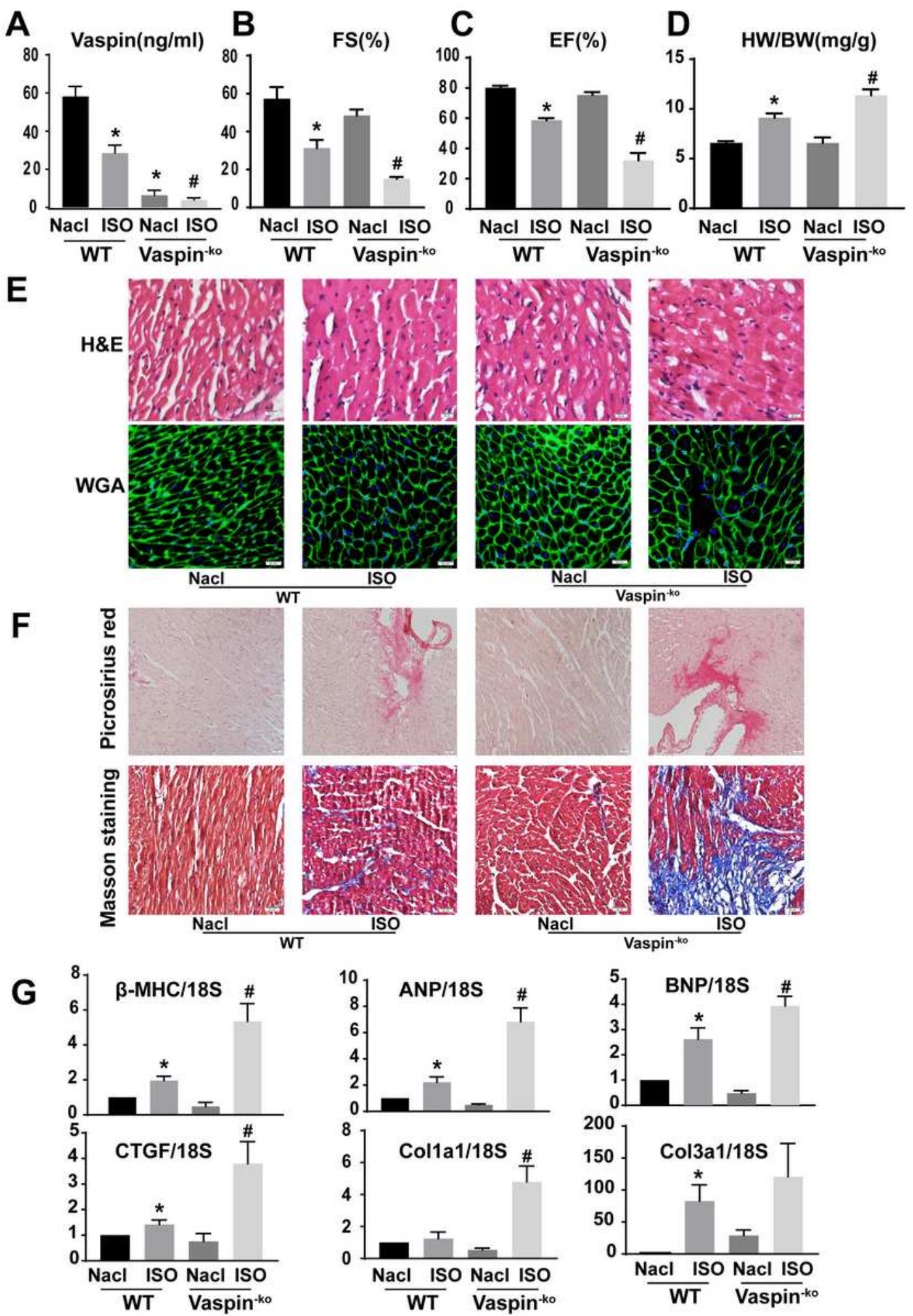

Figure 1

The effects of vaspin on ISO囚induced cardiac hypertrophy in vivo. 

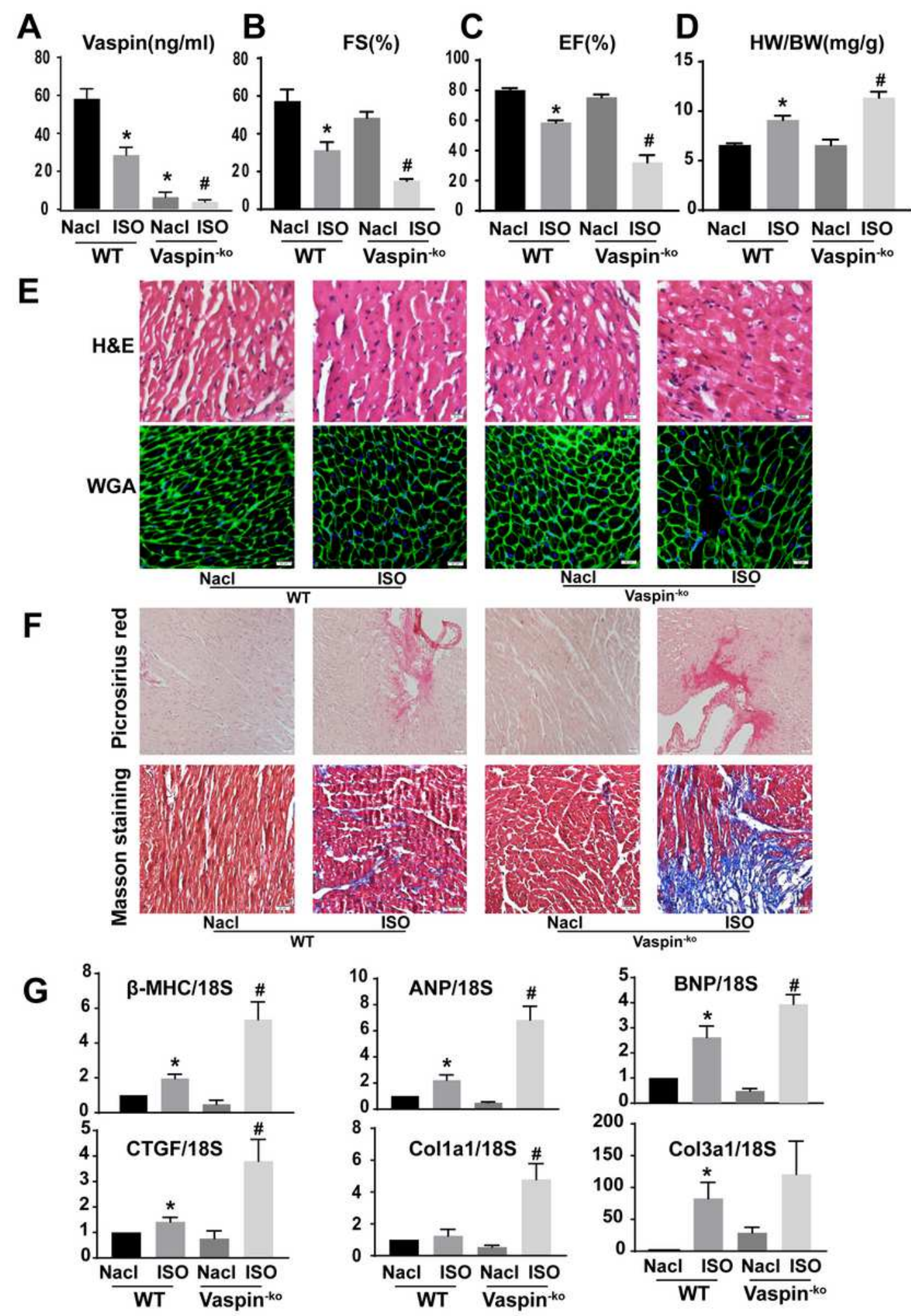

Figure 1

The effects of vaspin on ISO囚induced cardiac hypertrophy in vivo. 


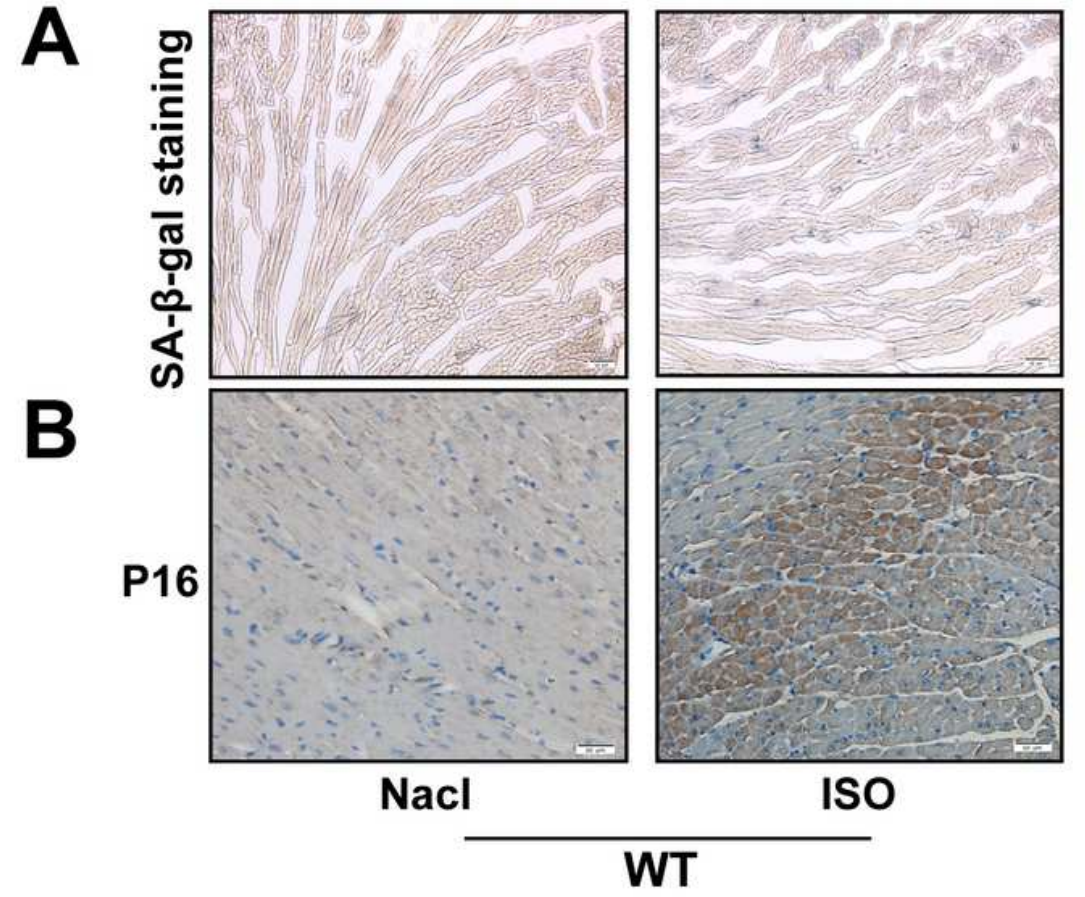

c

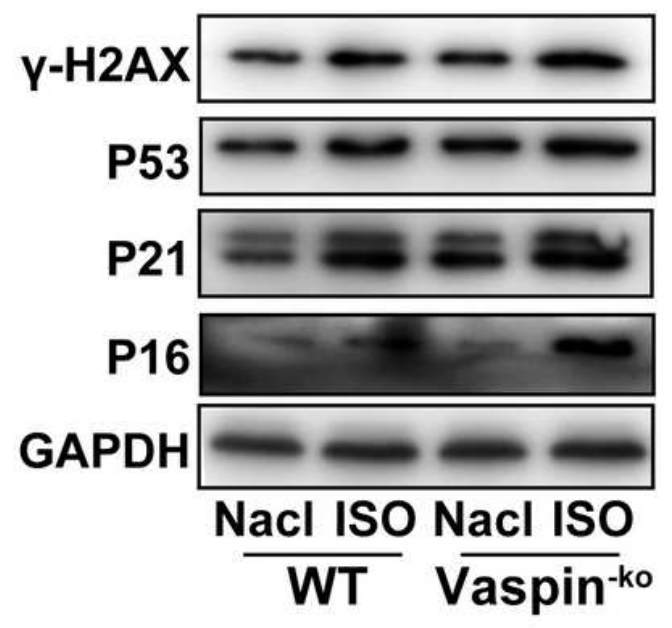

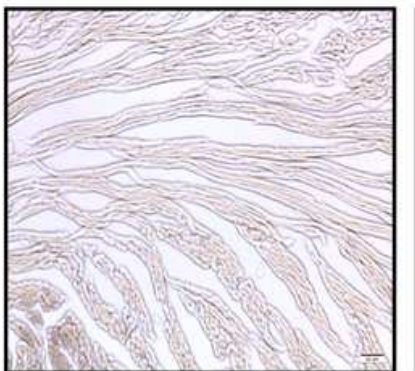

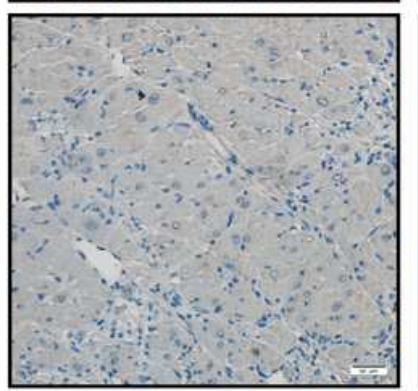

$\mathrm{Nacl}$
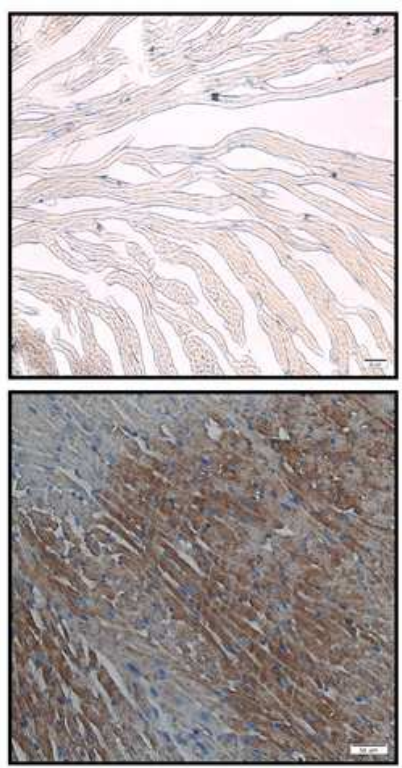

ISO

Vaspin ${ }^{-k o}$
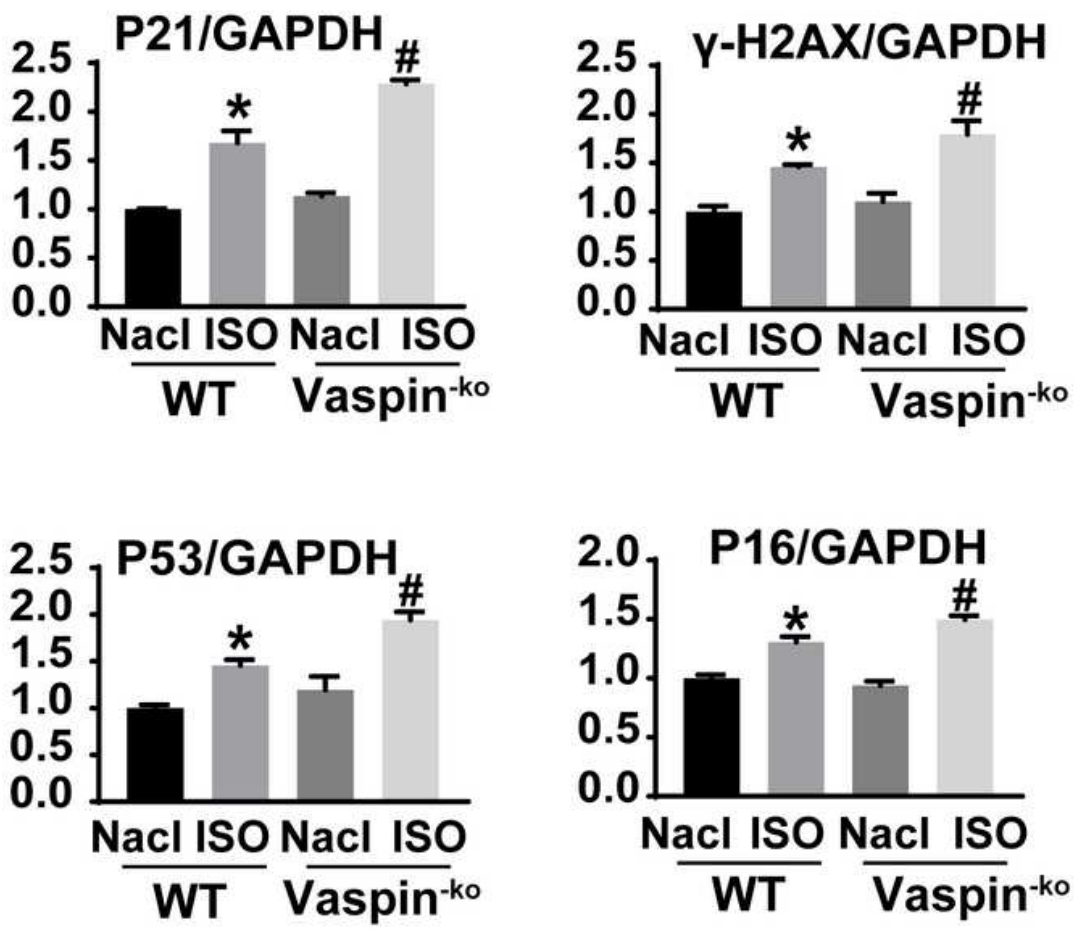

Figure 2

The effects of vaspin on ISO\induced premature myocardial senescence in vivo. 


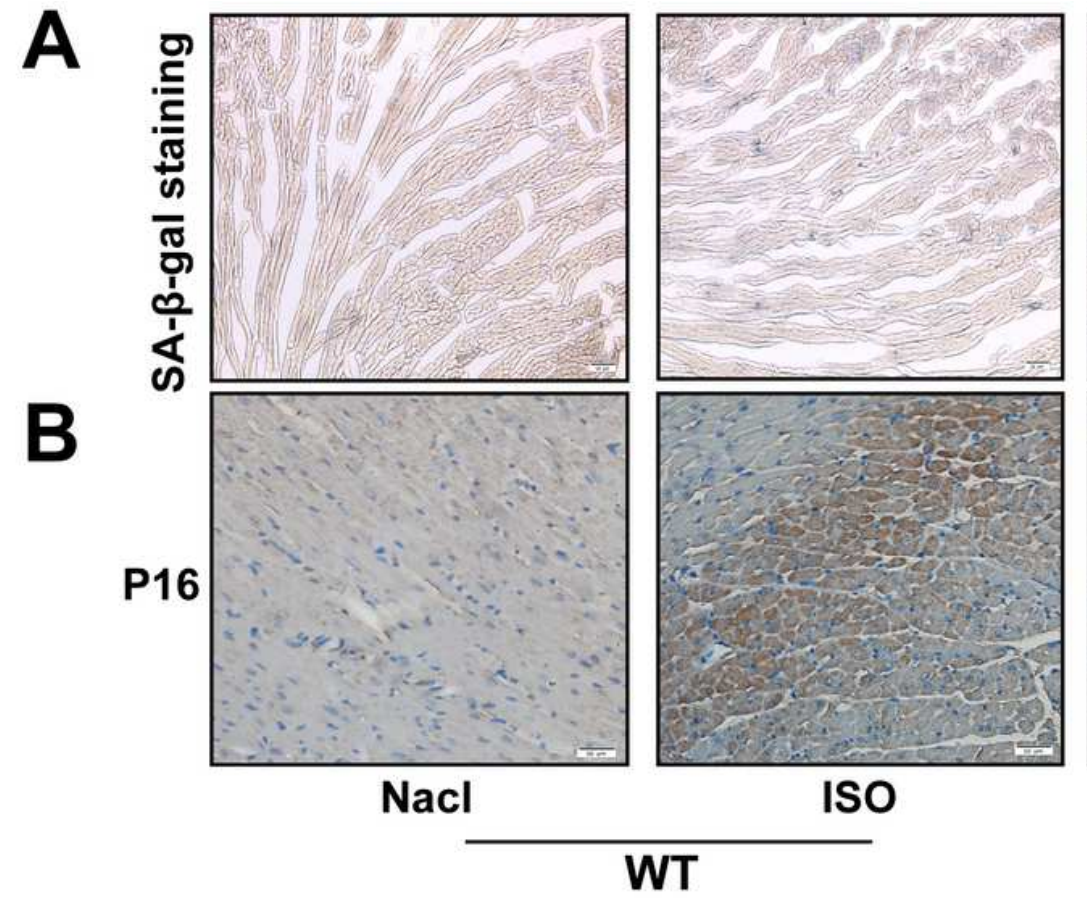

C

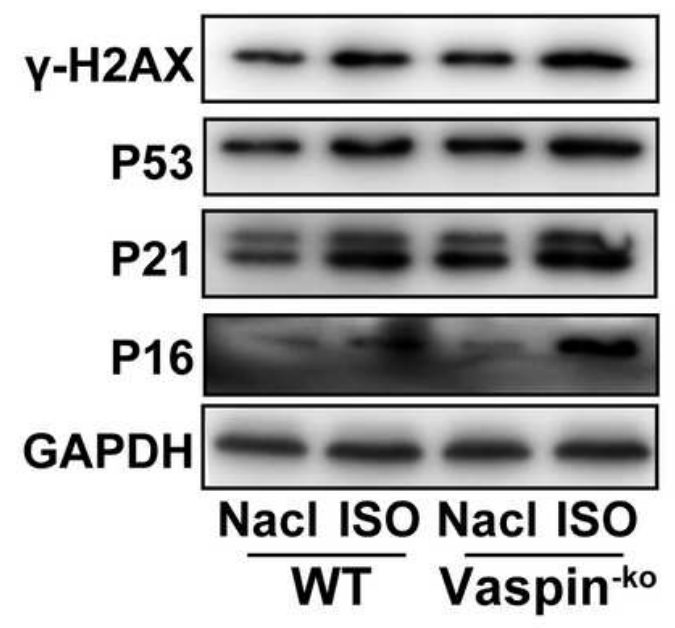

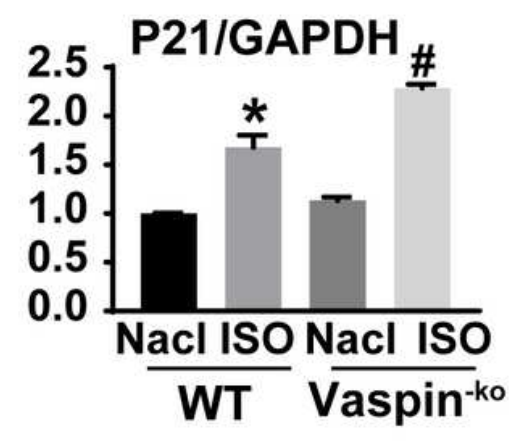

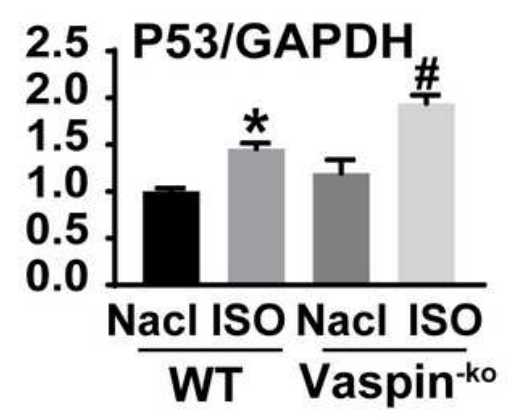

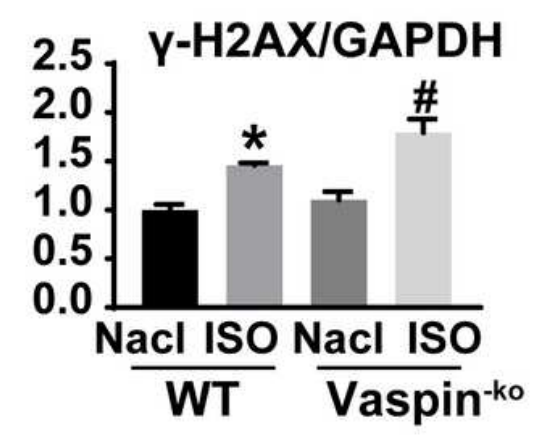

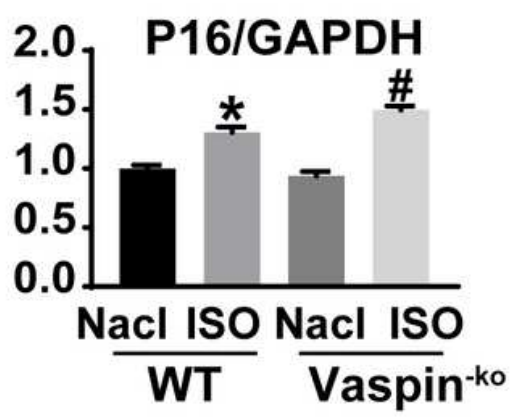

Figure 2

The effects of vaspin on ISO\induced premature myocardial senescence in vivo. 


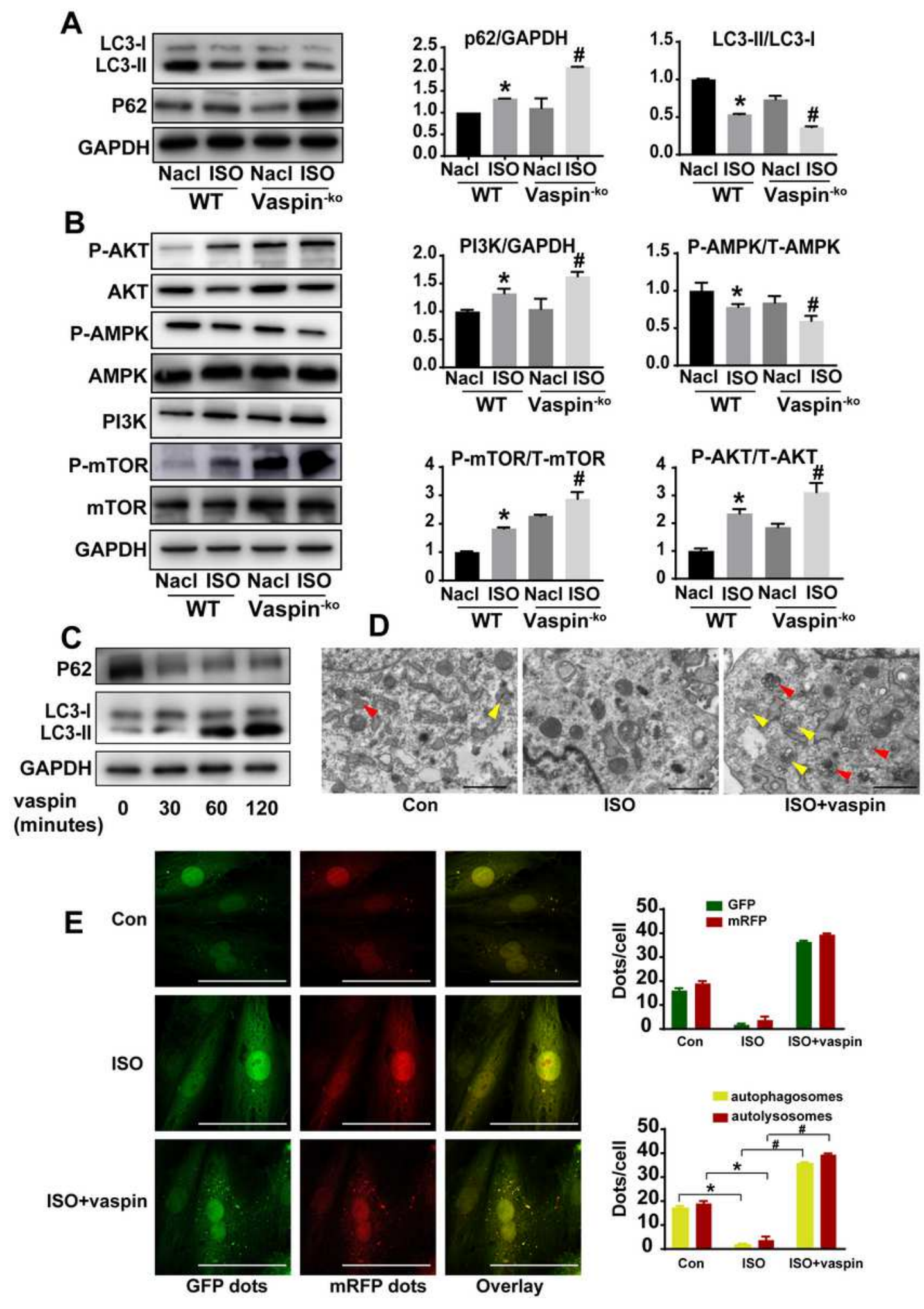

Figure 3

The effects of vaspin on ISO \induced autophagy reduction in vivo and vitro 


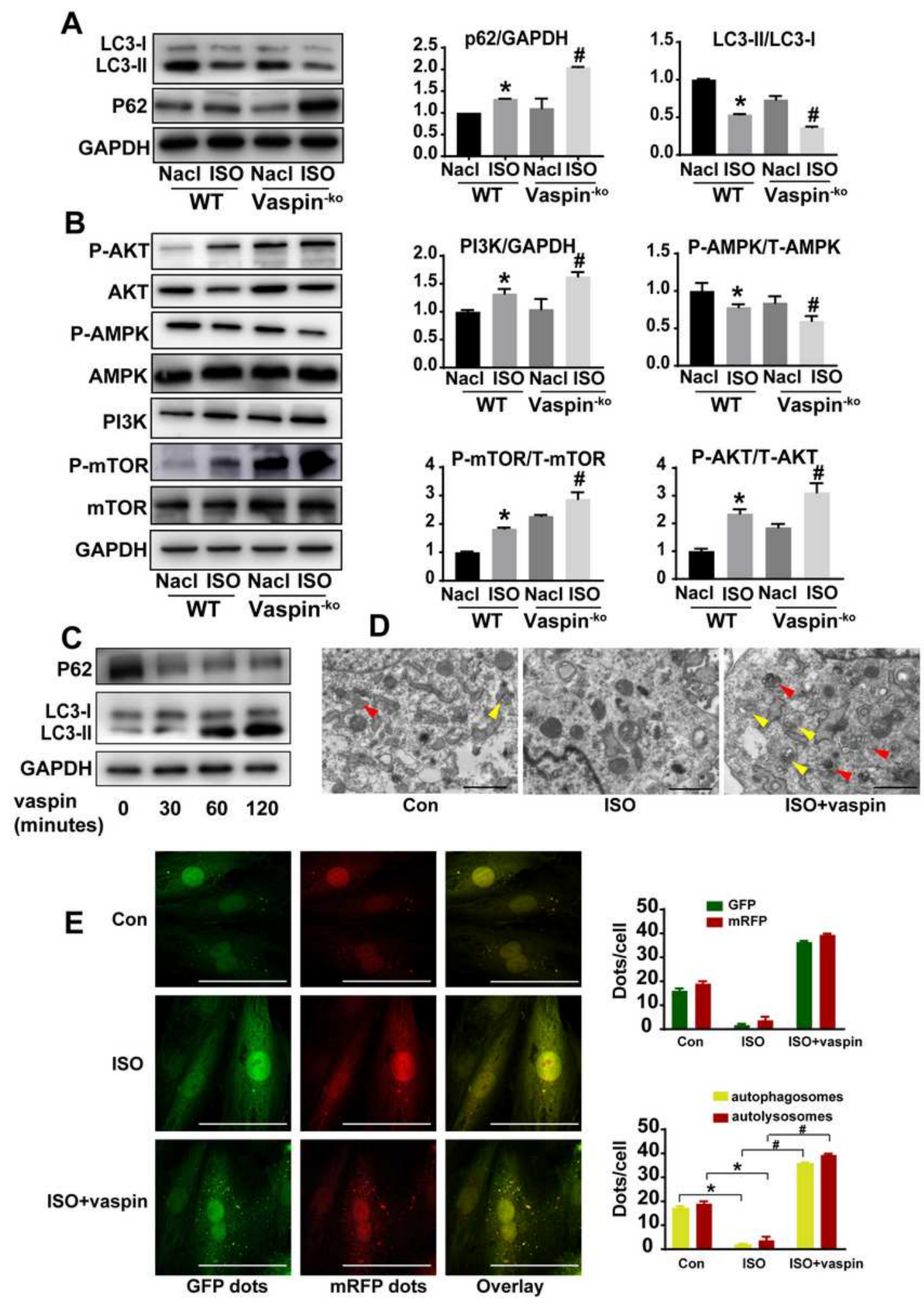

Figure 3

The effects of vaspin on ISO \induced autophagy reduction in vivo and vitro 
A

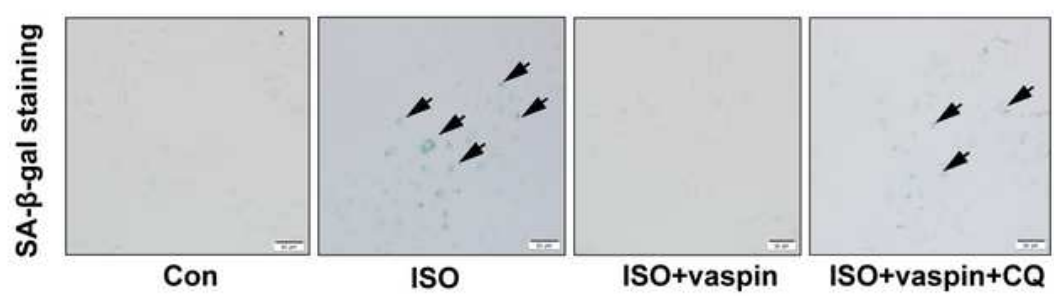

B
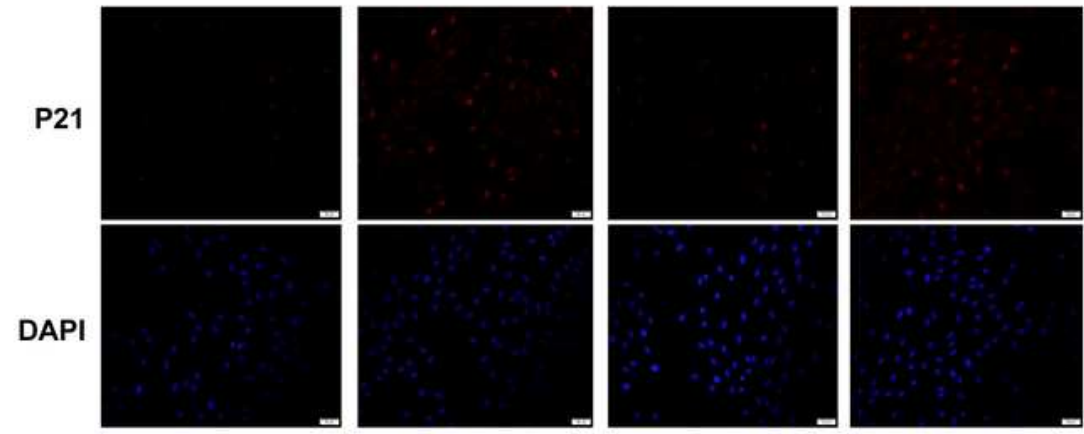

Merge
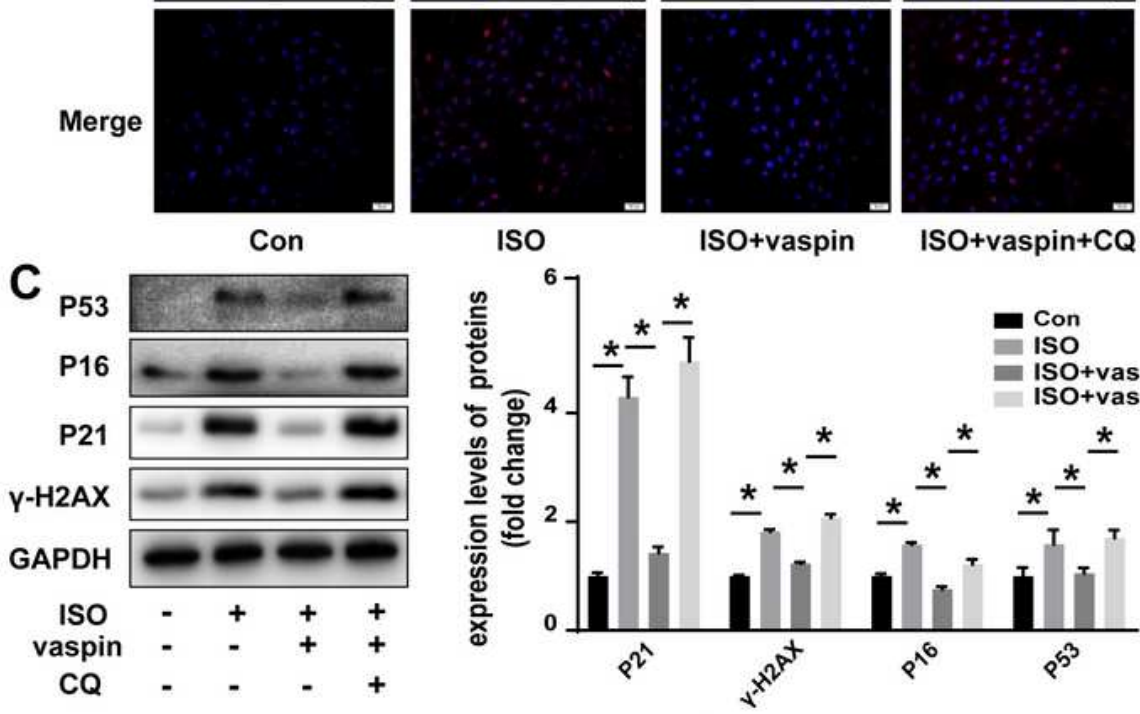

ISO+vaspin

ISO+vaspin+CQ

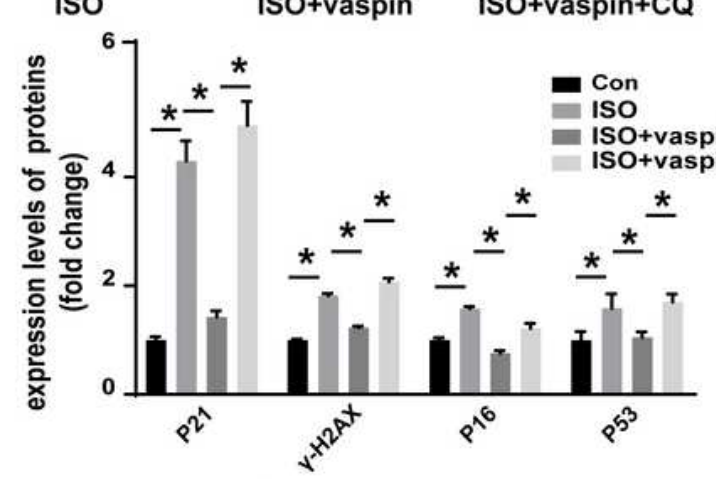

D

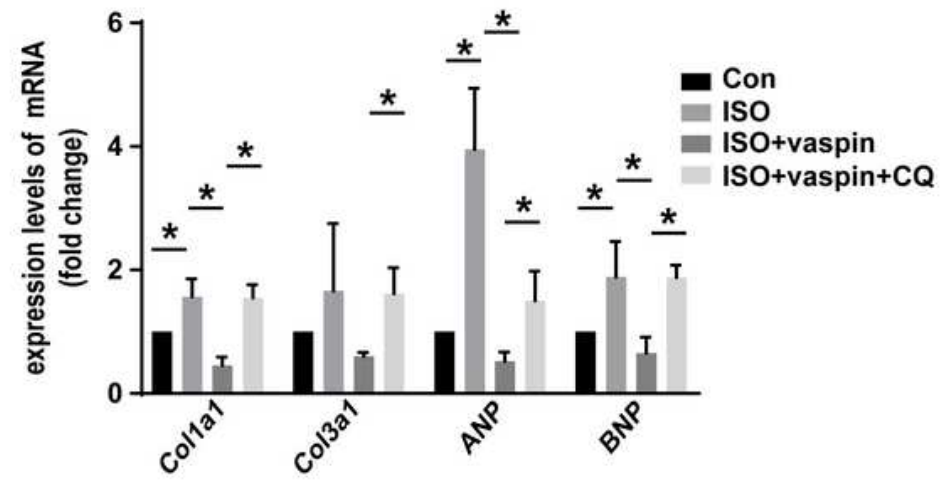

Figure 4

The protective effect of vaspin on cardiomyocyte hypertrophy and senescence was bloc ked by the autophagic flux blocker CQ in vitro. 
A

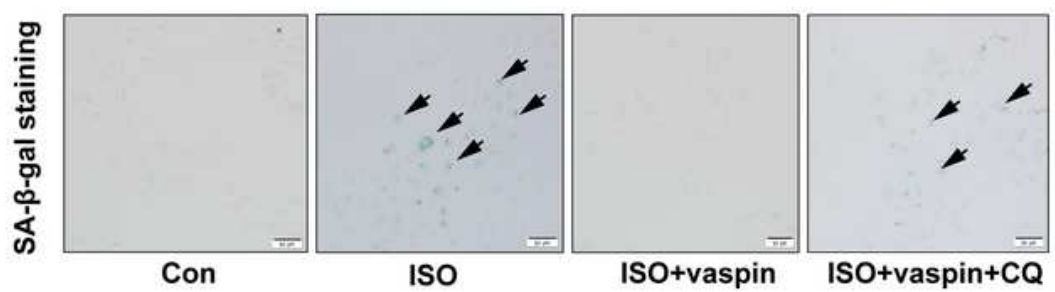

B

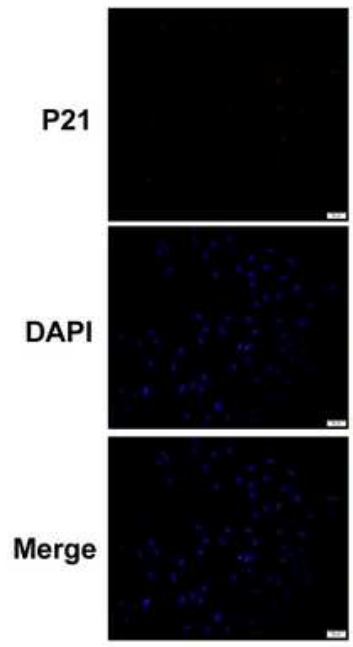

Con

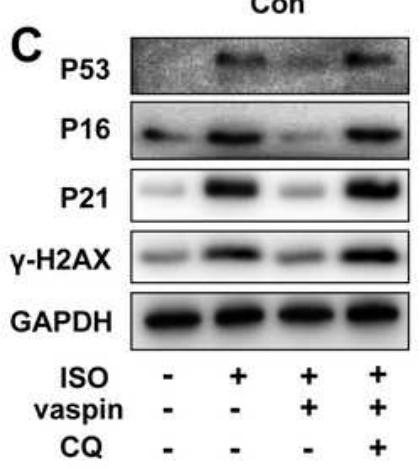

D

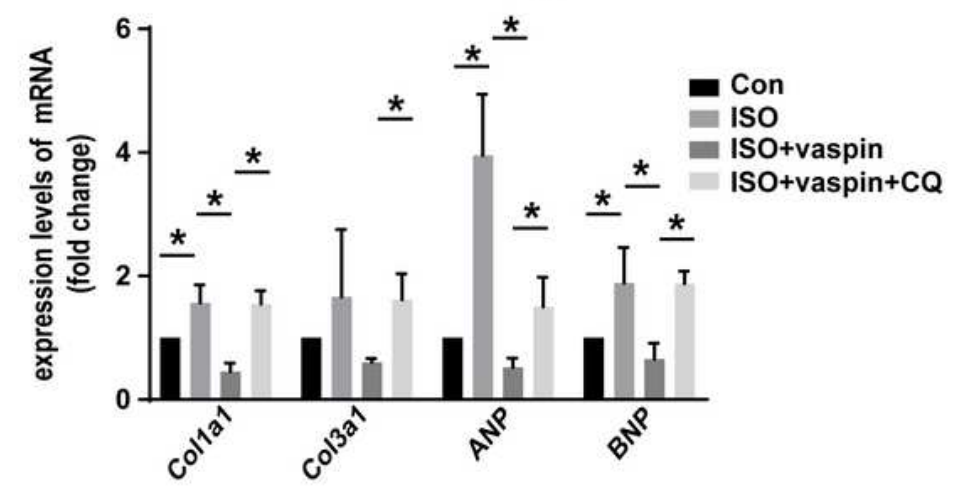

Figure 4

The protective effect of vaspin on cardiomyocyte hypertrophy and senescence was bloc ked by the autophagic flux blocker CQ in vitro. 


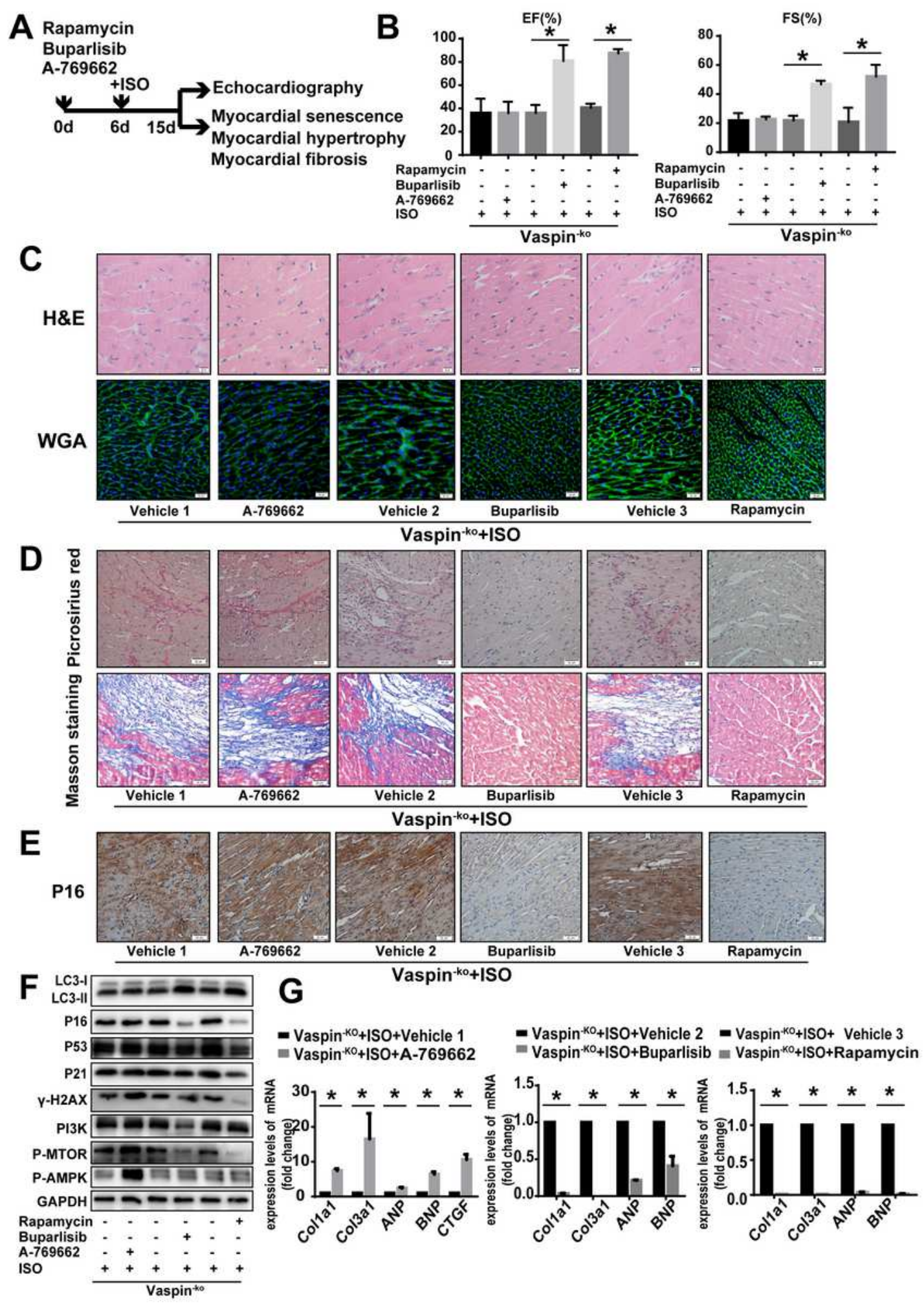

\section{Figure 5}

Fig. 5. The protective effect of vaspin on premature myocardial senescence and cardiac hypertrophy depends on the PI3K AKT mTOR pathway dependent activation of autophagy. 


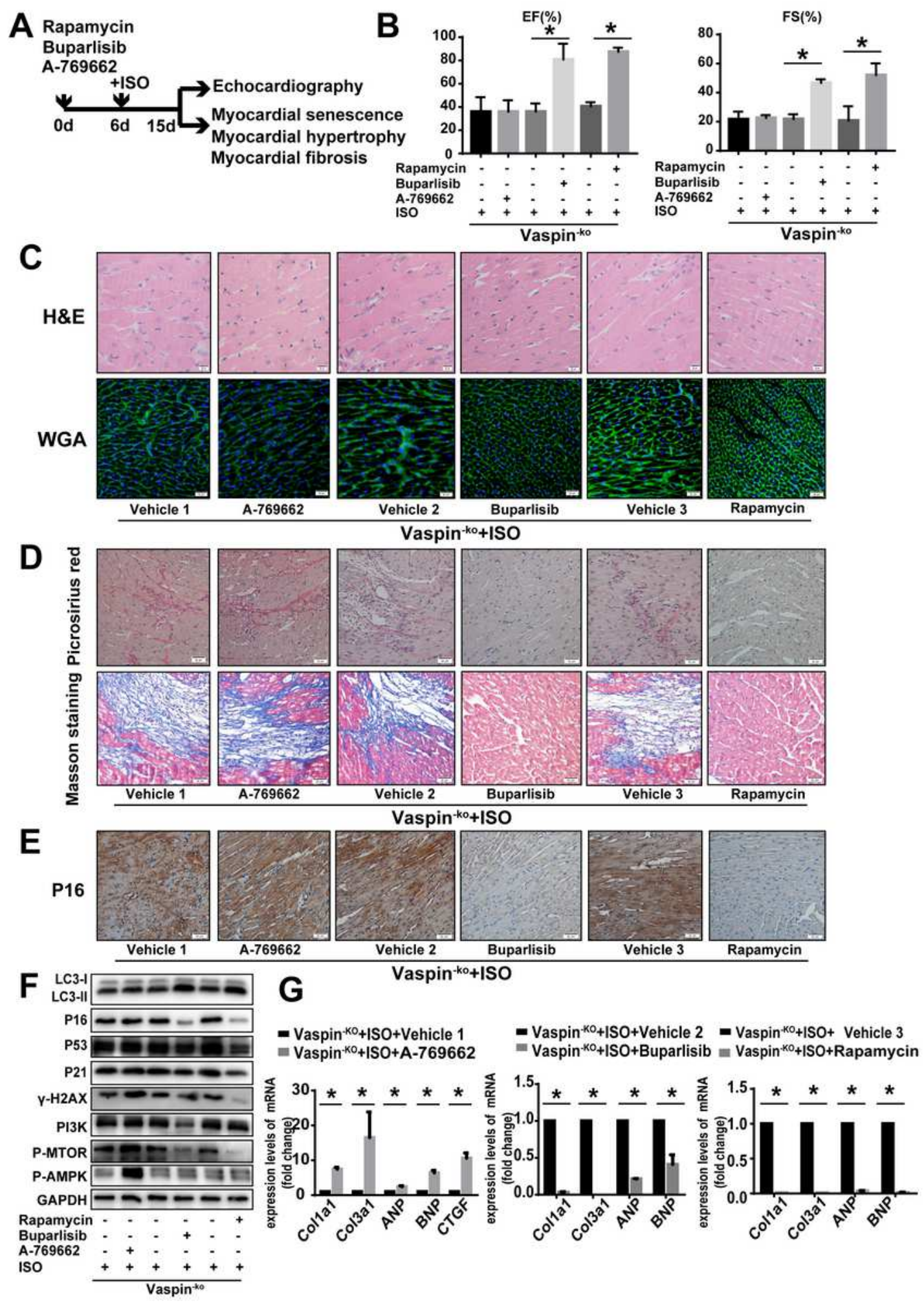

\section{Figure 5}

Fig. 5. The protective effect of vaspin on premature myocardial senescence and cardiac hypertrophy depends on the PI3K AKT mTOR pathway dependent activation of autophagy. 


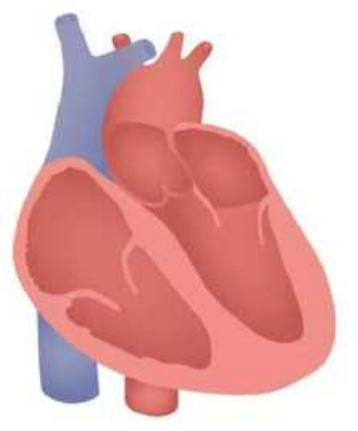

Normal heart
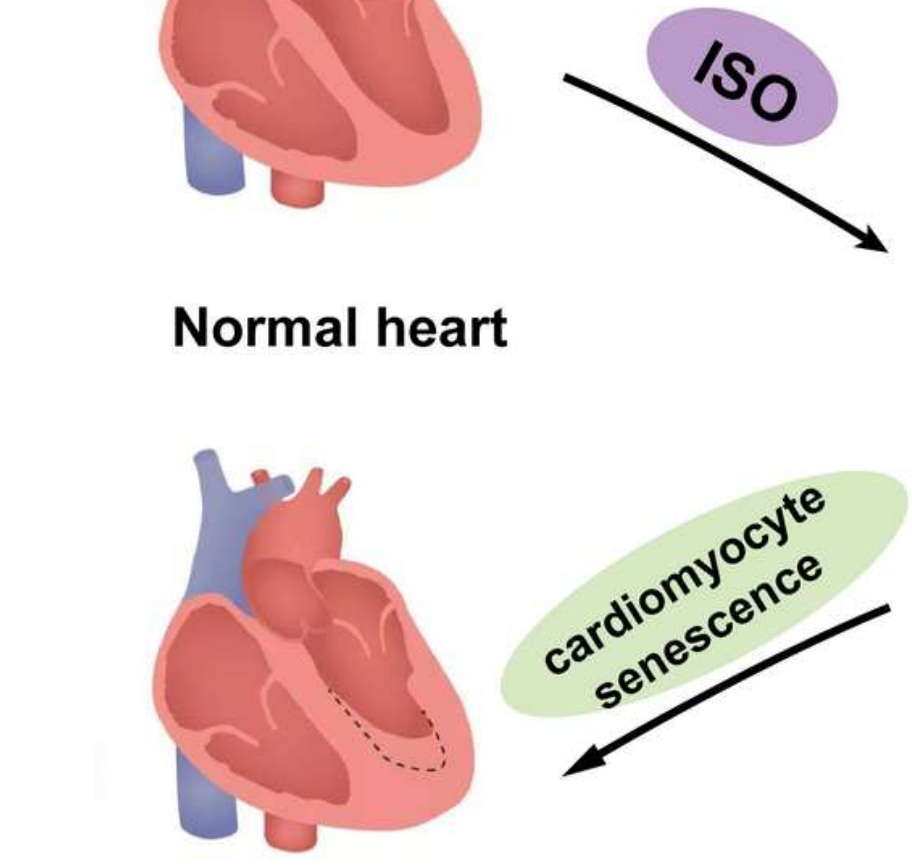

\section{Pathological cardiac hypertrophy}

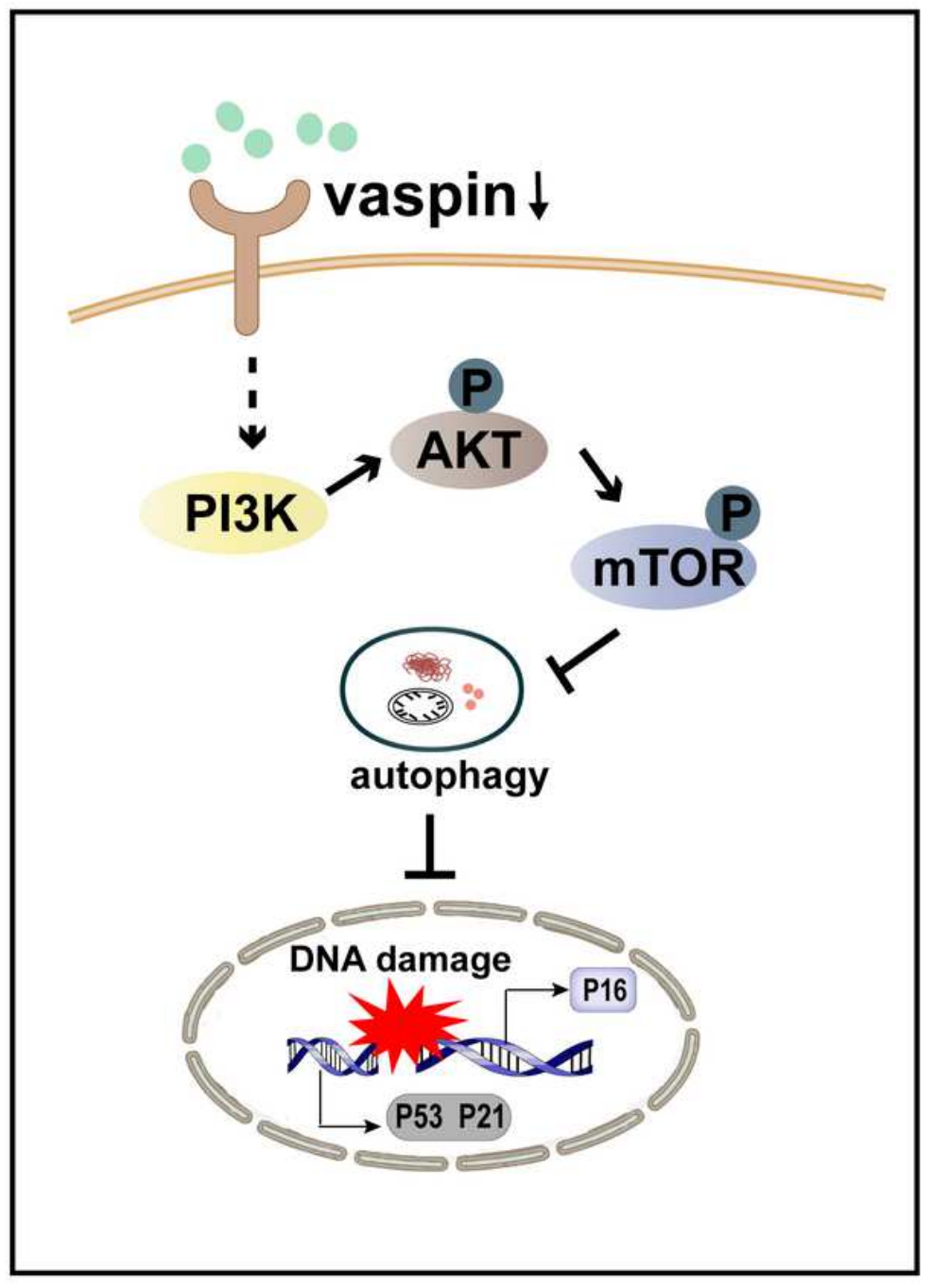

Figure 6

The proposed molecular mechanisms of the protective effect of vaspin on pathological cardiac hypertrophy. In summary, vaspin is involved in SO induced cardiac hypertrophy by impr oving impaired autophagy and reducing the proportion of senescent cardiomyocytes. 


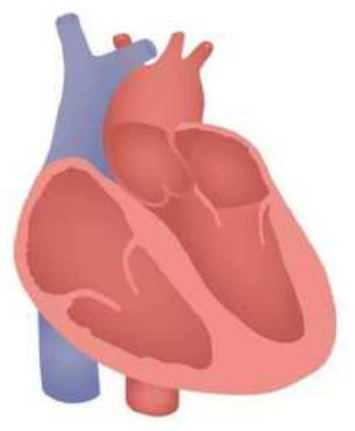

Normal heart
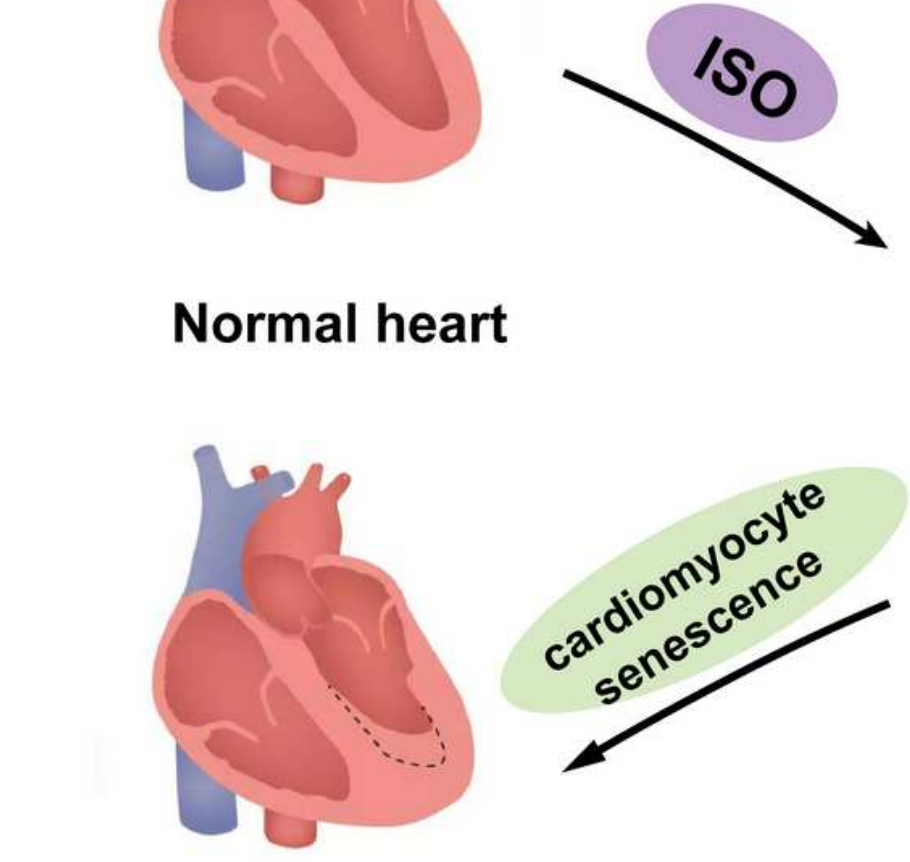

\section{Pathological cardiac hypertrophy}

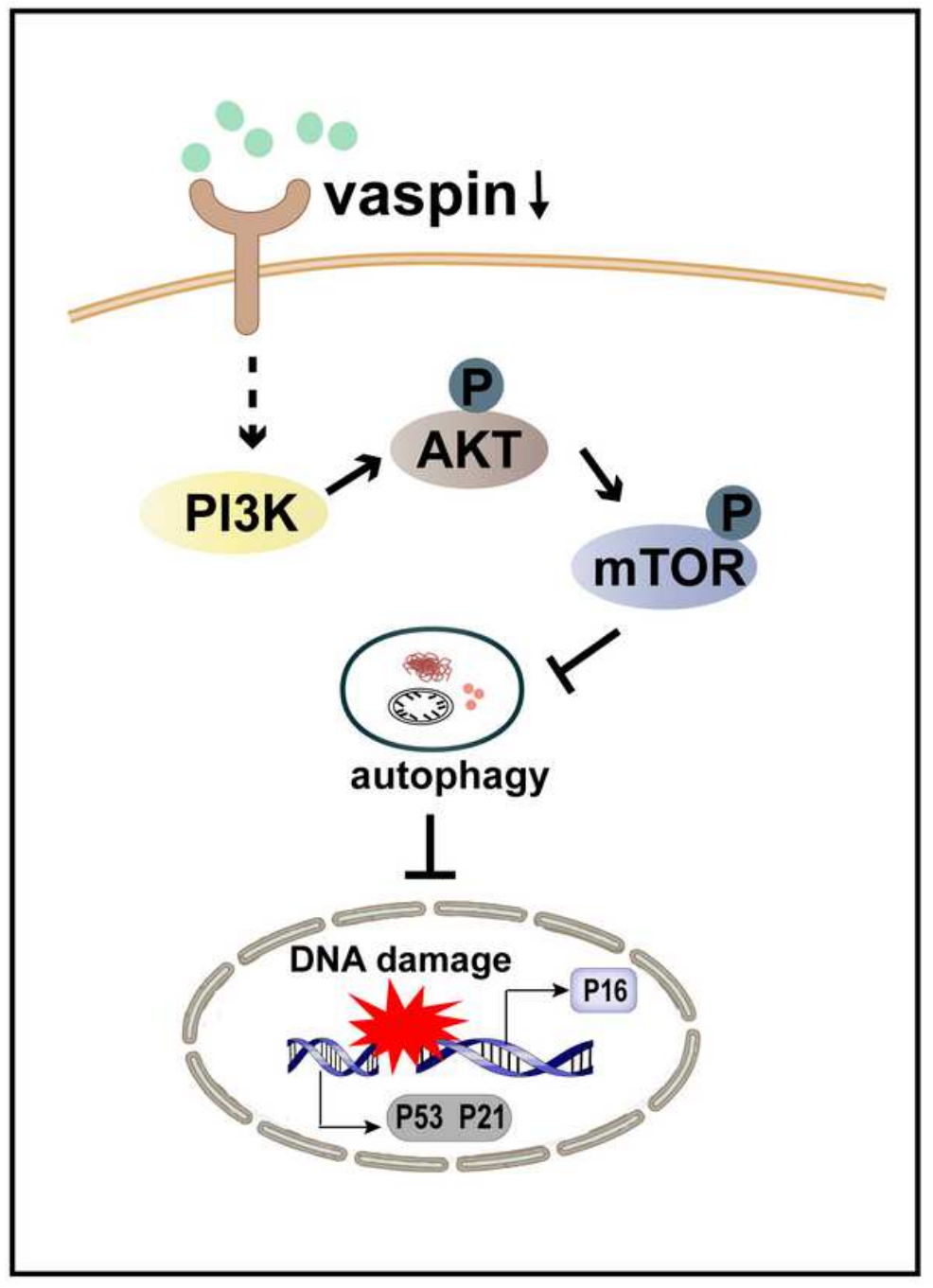

Figure 6

The proposed molecular mechanisms of the protective effect of vaspin on pathological cardiac hypertrophy. In summary, vaspin is involved in SO induced cardiac hypertrophy by impr oving impaired autophagy and reducing the proportion of senescent cardiomyocytes. 